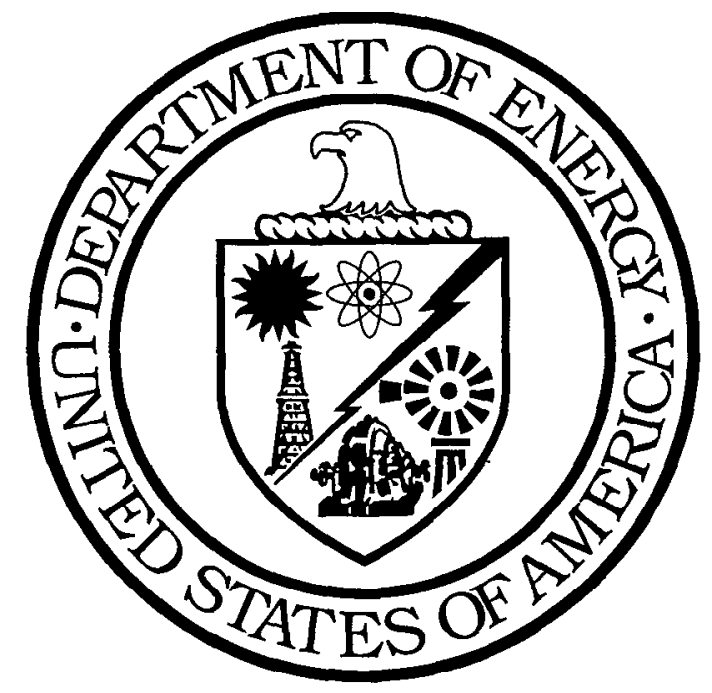

\title{
Multiple Programs Essential to the Scientific Vitality of the DOE Defense Program Laboratories
}

\author{
July 1997
}

U.S. Department of Energy

Office of Defense Programs

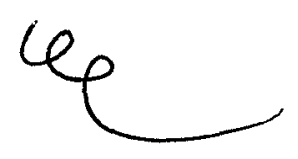




\section{Contents}

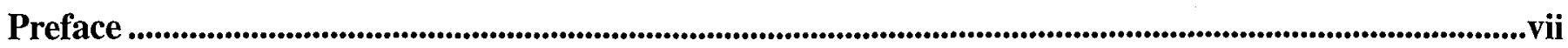

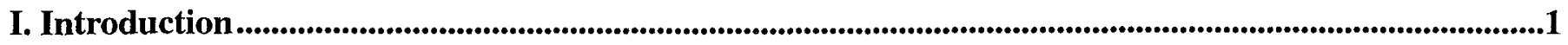

II. Nuclear Security in the Post-Cold War Era ..............................................................................................................4

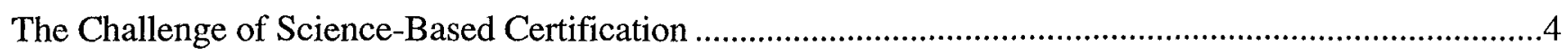

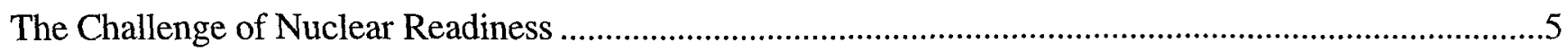

III. Scientific Vitality at the DP Laboratories ........................................................................................................8

IV. The DP Laboratories: Meeting the Challenge ..................................................................................................11

Benefits of Other Programs to the DP Laboratories' National Security Mission .......................................12

Magnetic Fusion Energy, Strategic Defense, and Advanced Hydrotesting ...........................................13

Energy and Environmental Research Computer Codes and Weapons Safety ..........................................18

Deep Borehole Disposition of Plutonium from Dismantled Weapons ................................................18

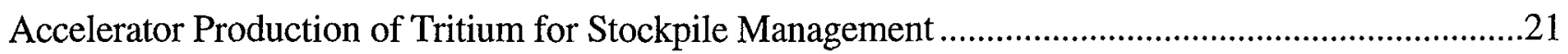

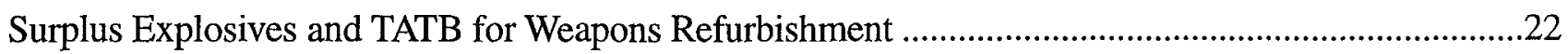

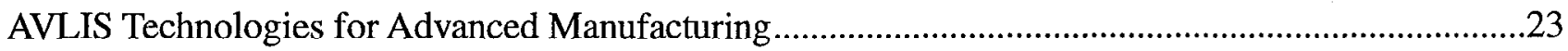

Pulsed Power, Advanced Manufacturing, and Weapons Research............................................................24

Plasma Technologies and Weapons Complex Cleanup ……….............................................................24

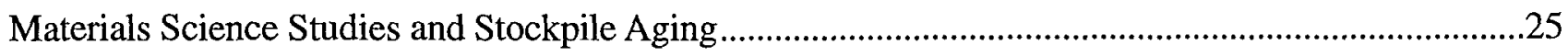

SQUIDs, Brain Imaging, Nonproliferation, and Stockpile Surveillance ...............................................26

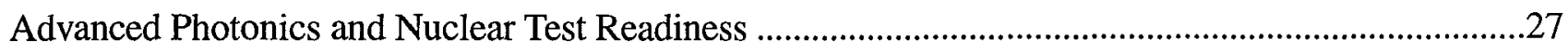

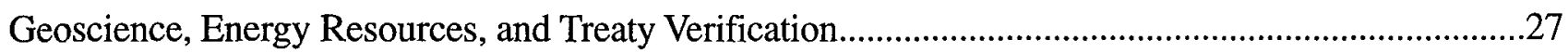

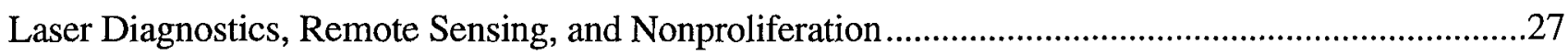

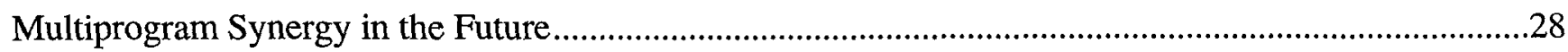

\section{Conclusion: Multiple Programs Enhance the DP Laboratories'}

National Security Mission 
DOE and Laboratory contacts:

Peter D. Barnes (Los Alamos)

John Cummings (Sandia)

Jay Edgeworth (DOE/DP)

Richard Fortner (Livermore)

Maurice Katz (DOE/DP)

Lauren de Vore (Livermore, writer/editor)

Gerald Green (DOE/DP)

Andrew Hazi (Livermore)

Carl Poppe (University of California)

Paul Shoemaker (Sandia, facilitator)

Kimberly Thomas (Los Alamos) 


\section{Preface}

The future of the Department of Energy's Defense Program (DP) laboratories - Los Alamos, Livermore, and Sandia-has been extensively debated and examined over the past several years. To assist in this process, I have asked that a set of documents be prepared, which, when taken together, present a comprehensive picture of the three laboratories.

This document describes the multiprogram nature of the DP laboratories and the value of their involvement in non-DP work as it relates to the nuclear weapons program. The other two documents, Integration and Collaboration...Solving Science and Technology Problems for the Nation (DOE/DP-96009797) and Roles and Responsibilities of the Department of Energy Nuclear Weapons Laboratories in the Stockpile Stewardship and Management Program (DOE/DP-97000280), describe respectively the integrated nature of the DP laboratories and the roles of the laboratories as they meet their individual and collective responsibilities of ensuring the safety and reliabilities of the U.S. nuclear weapons stockpile.

The scientific and technical challenges inherent in the DP laboratories' national security responsibilities today are as complex as those during the Manhattan Project and the Cold War years. Science-based stockpile stewardship and management require in-depth understanding of the full spectrum of nuclear weapons science and technologyphysics, chemistry, materials, manufacturing, computational modeling, engineering, and electronics, to name a few-as well as a combination of capabilities and facilities unavailable anywhere else in the country.

In addition to stockpile stewardship and management, many other nationally important issues involve science and technology - for example, nuclear nonproliferation, energy security, and environmental protection and remediation. Over the years, the DP laboratories have applied expertise and technologies developed in their nuclear weapons work to these other issues, focusing on those areas where they can make unique and valuable contributions.

The nation has invested substantially in the three DP laboratories, creating an unmatched resource of scientific and engineering expertise, facilities, and capabilities. In this era of tight budgets, it is important that the laboratories extract maximum leverage from this investment and fulfill their nuclear weapons responsibilities as cost-effectively as possible.

The multiprogram nature of the DP laboratories has been key to their success in achieving the outstanding level of scientific and technical excellence that has become their hallmark and in carrying out their national security mission. The multiprogram work of the laboratories also provides an extremely effective way of leveraging the nation's investment in science and technology. It makes sense for the DP laboratories to apply their expertise to non-nuclear-weapons programs of national importance. It also makes sense for the DP laboratories to collaborate with other government laboratories, universities, and industry to apply the unique expertise, facilities, and capabilities of these institutions to national security challenges.

This report briefly reviews the challenges faced by the DP laboratories in fulfilling their stockpile stewardship and management responsibilities. It then discusses the benefits of the synergy and the accelerated pace of scientific achievement that arise from the laboratories' multiple programs. A representative selection of accomplishments is presented that illustrates the importance of the contributions made to the laboratories' national security mission by their non-nuclear-weapons projects and their connections with the wider scientific community.

The laboratories' history of accomplishments attests to the success of their multidisciplinary, multiprogram approach to technical problem solving. Now and in the future, the institutional vitality required for the DP laboratories' national security mission depends on their integrated, multidisciplinary and multiprogram nature. Indeed, the multiprogram nature of the laboratories is essential for their continued ability to carry out their primary mission.

Victor H. Reis

Assistant Secretary for Defense Programs

U.S. Department of Energy 



\section{Introduction}

IN carrying out their national security mission, the three DOE Defense Program laboratories-Los Alamos, Livermore, and Sandiahave extended the frontiers of many areas of science and technology. Today, these laboratories are recognized as world leaders in atomic, nuclear, and plasma physics as well as in computing and numerical simulation, lasers and electro-optics, materials science and precision fabrication, advanced sensors, miniaturized electronics and instrumentation, and even human genetics and environmental science.

A hallmark of the Defense Program (DP) laboratories is their multidisciplinary approach to solving complex scientific and technical problems. Nuclear weapons work (be it the design and development assignments of the past or the stewardship responsibilities of today and the future) involves many disciplines of science-- physics, chemistry, materials, engineering, and computation, among othersplus a wide spectrum of technologies-explosives, electronics, instrumentation, aerodynamics, and automated control, to name a few (see Table 1).

Major inventions and breakthroughs have been made by the DP laboratories in the course of their nuclear weapons work that have spun out to provide the basis for new capabilities and new non-

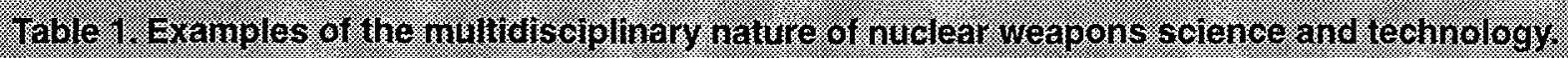

\section{Discipline 10.0 Key areas. weapons applications}

\begin{tabular}{|c|c|}
\hline nce & 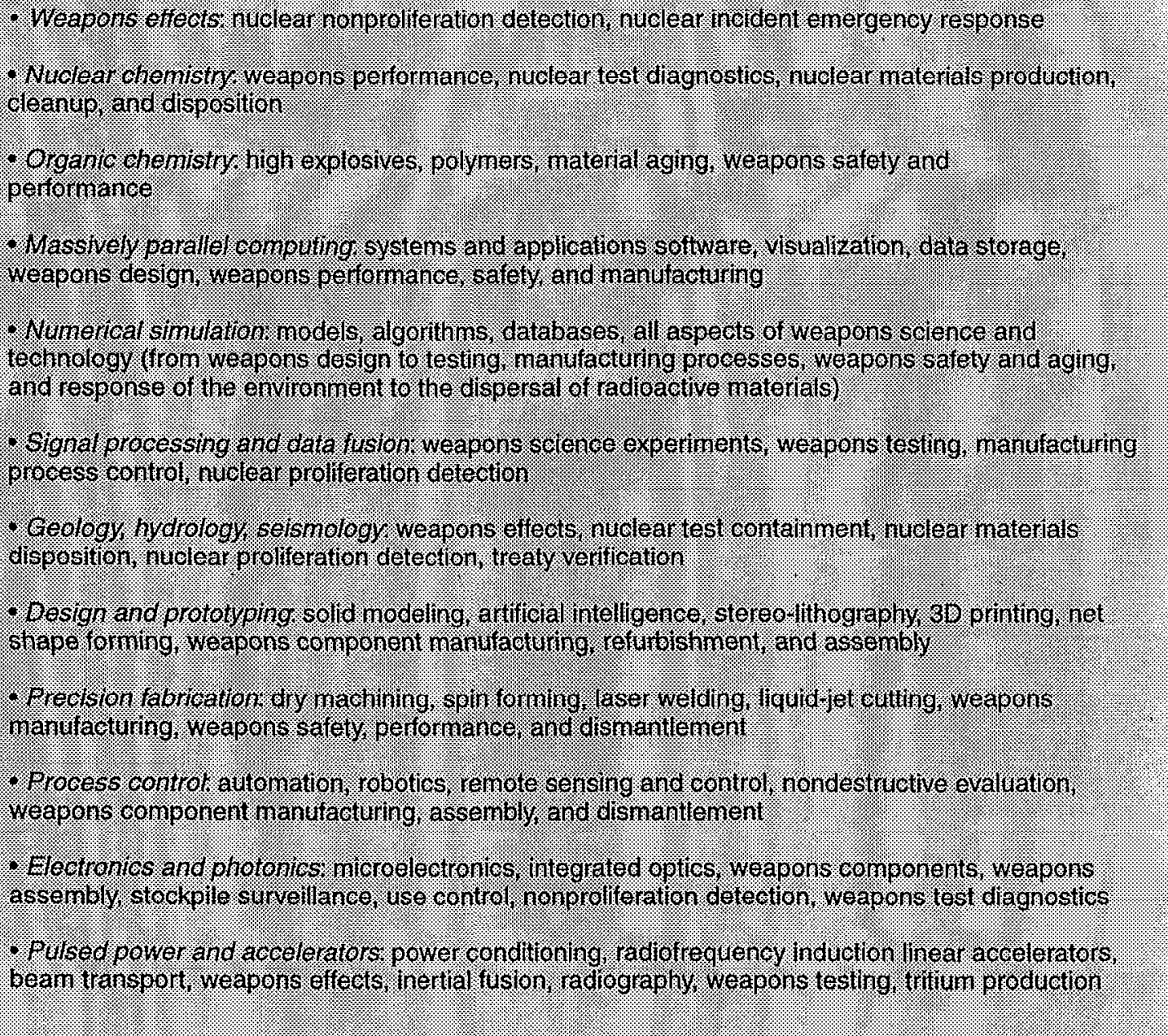 \\
\hline
\end{tabular}




\section{Table 1. Continuled:}

\section{Discipline}

Lasers and opties

Materials science

\section{Key areas: weapons applications}

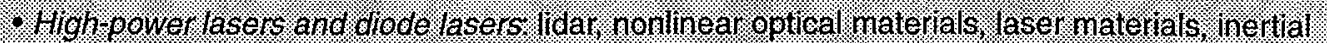

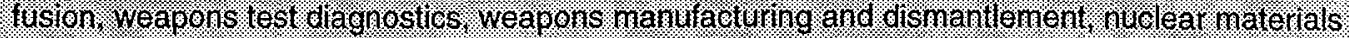

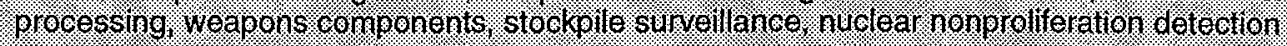

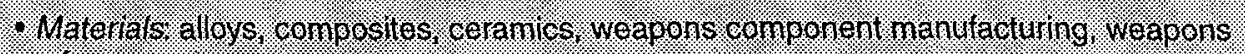
perfornance

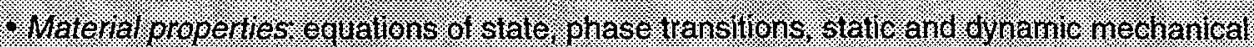

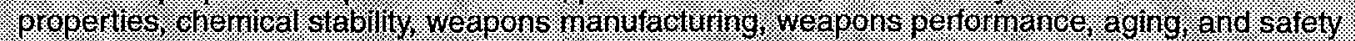

Plinsics

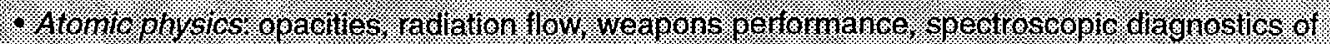
Inertial U sion plasmas

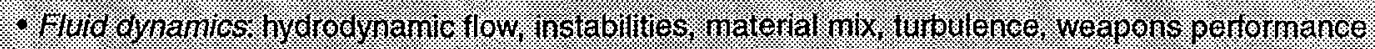

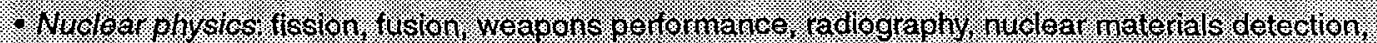

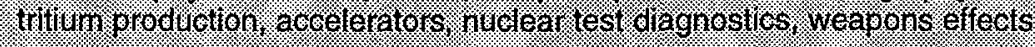

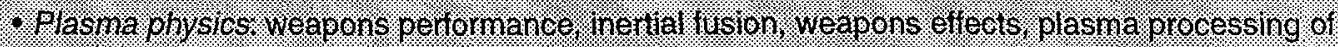
naterials. weapons programs. In many instances, further capabilities and innovations developed through these new programs have spun back to benefit the laboratories' national security mission.

For example, the idea of laserdriven nuclear fusion had not been conceived when the laboratories were founded. When the concept of the laser was first proposed (in 1958, by Charles H. Townes and Arthur I. Schalow), scientists at the DP laboratories drew on their experience with thermonuclear fusion in nuclear weapons and began investigating the possibility of using lasers to drive the fusion reaction in the laboratory. Through these efforts, they advanced the state of the art in electro-optics, microfabrication, plasma physics, and many other areas. Today, Livermore is a world leader in laser science and technology. This expertise is spinning back to benefit the laboratories' nuclear weapons mission, as it enables them to design and construct the National Ignition Facility, a crucial experimental facility for stockpile stewardship and management (Figure 1).

For another instance, the laminar-flow clean room was invented by Sandia in the 1960 s for weapons assembly. The techniques and technologies devised for ultraclean parts fabrication and assembly enabled the entire microelectronics industry. Microelectronics are now integral to nuclear weapons technology and to many aspects of stockpile surveillance and maintenance (Figure 2).

The transition to science-based stewardship of the U.S. nuclear stockpile (from the nuclear-testbased approach of years past) presents major new challenges to the DP laboratories as they carry out their primary mission-namely, ensuring the safety and reliability of the U.S. nuclear arsenal. Indeed, one must not underestimate the risks and uncertainties involved in this new approach to stewardship and management of the enduring U.S. stockpile. It will take at least a decade to develop the necessary new capabilities, bring upgraded and new facilities on line, and acquire sufficient experience within the Stockpile Stewardship and Management Program to evaluate the adequacy of the program and determine the need for any changes.

Particularly during this period of transition, the institutional vitality required by the DP laboratories to carry out their national security mission depends heavily on their integrated, multiprogram nature and on their multidisciplinary approach to solving complex scientific and technical problems. By exploiting the synergy of multiple programs, Los Alamos, Livermore, and Sandia can ensure their ability to meet their national security responsibilities, help solve other nationally important problems, and maximize the return on investment that the nation has made in these laboratories. 


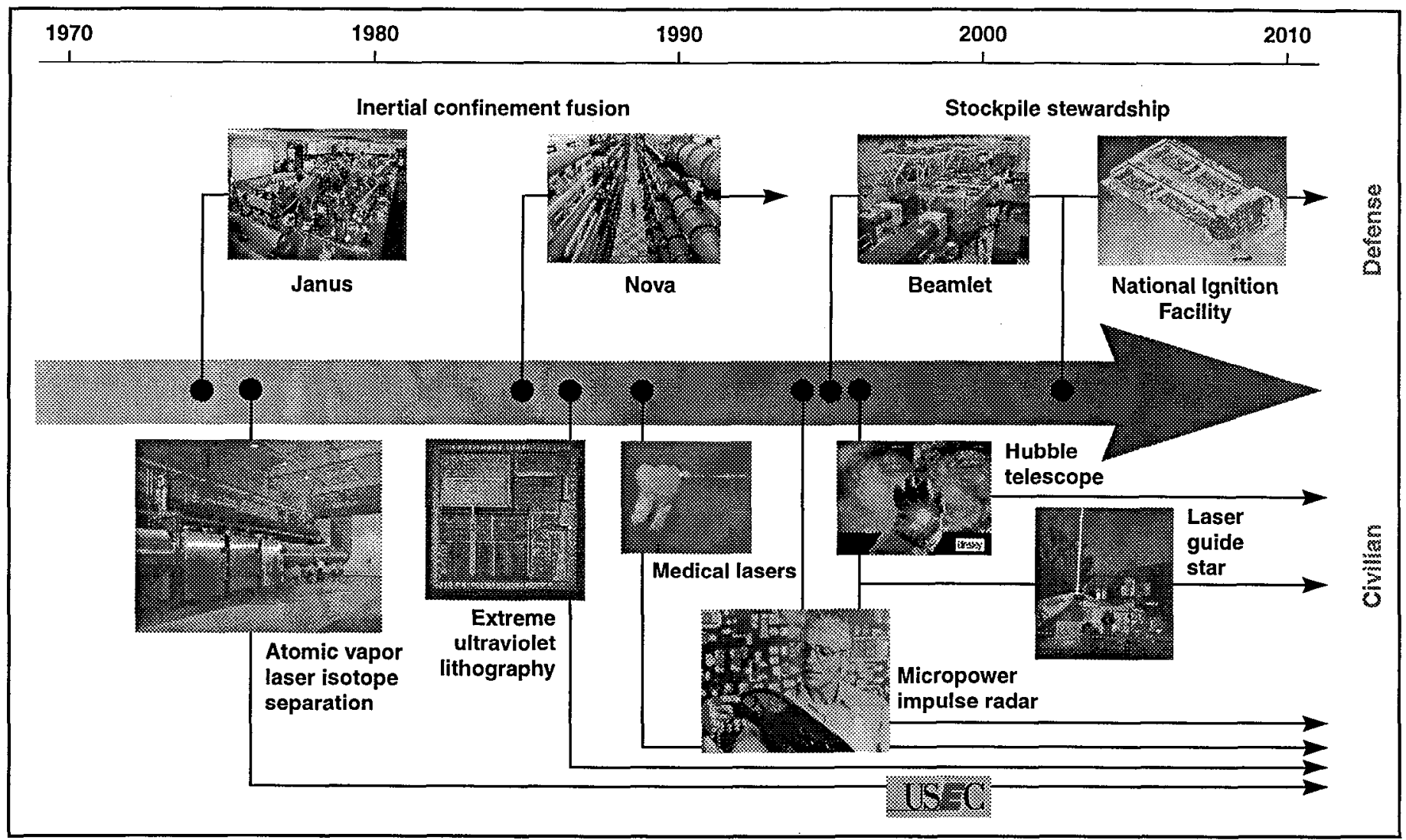

Figure 1. Advances made by the DP laboratories in laser science and technology have spun out to the civilian industrial sector, and advances there are spinning back to benefit the laboratories' national security work.

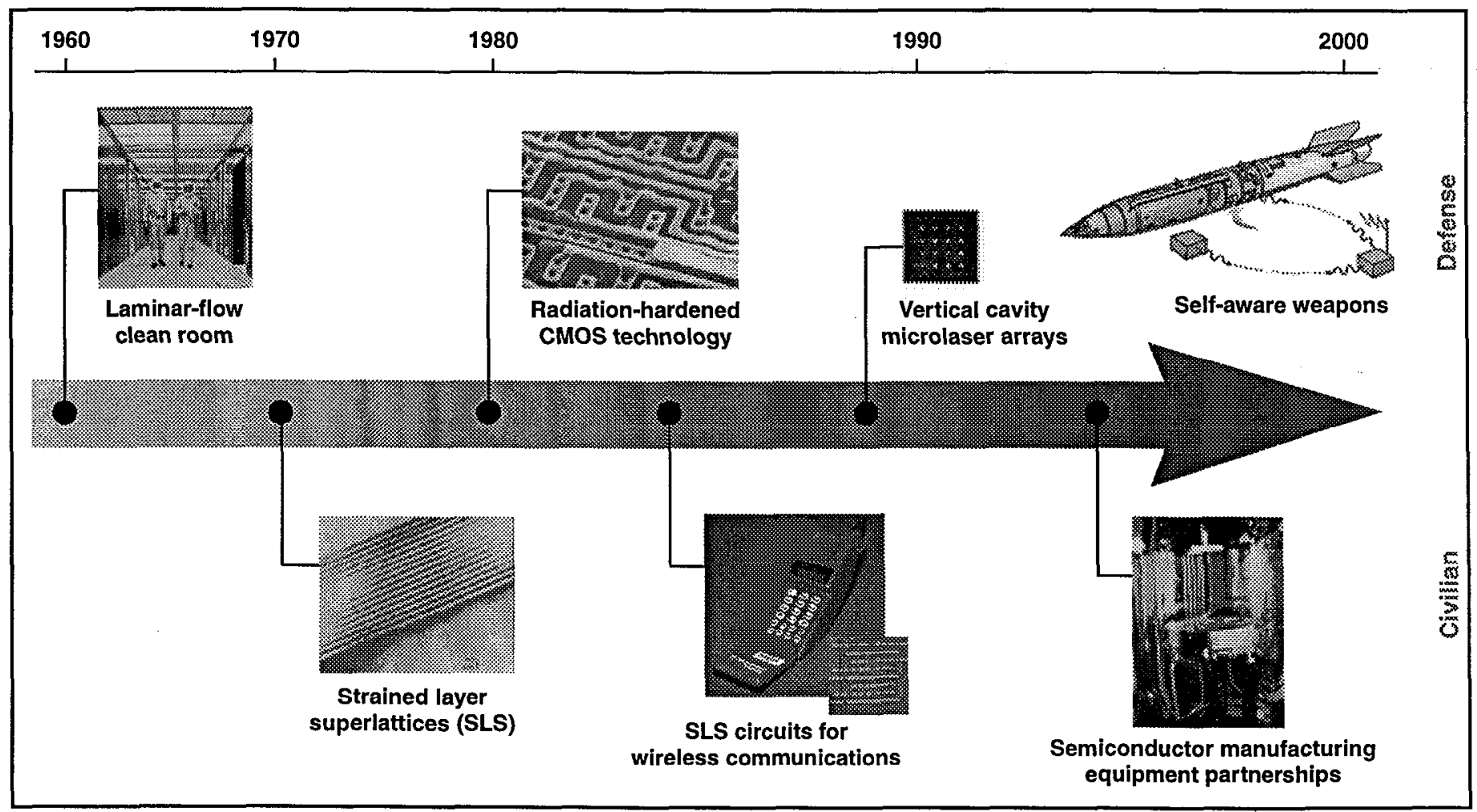

Figure 2. Techniques and technologies devised by the DP laboratories for ultraclean parts fabrication and weapons assembly were critical enabling elements for the entire microelectronics industry. 


\section{Nuclear Security in the Post-Cold War Era}

$\mathbf{W}_{\text {ITH the end of the Cold War, }}$ the U.S. has stopped underground nuclear testing and has signed a Comprehensive Test Ban Treaty (CTBT). The production of newdesign nuclear weapons has been halted and the size and diversity of the U.S. nuclear stockpile is being greatly reduced. However, nuclear deterrence remains an integral component of U.S. national security policy.

Official U.S. nuclear weapons policy is based on the Nuclear Posture Review, conducted by the Secretary of Defense and approved by the President in September 1994. This "lead plus hedge" policy states that the U.S. will lead in the careful downsizing of its nuclear stockpile while hedging against an uncertain future by maintaining the capabilities needed to reverse course in terms of stockpile size, nuclear testing, and new weapon design and production.

Thus, the DOE and the DP laboratories have a dual charge: (1) to certify the safety, security, and reliability of the U.S. nuclear stockpile without nuclear testing and without new-design weapon production, and (2) to preserve the intellectual and technical capabilities for performing nuclear tests and producing new-design nuclear weapons.

In addition, fiscal constraints are compounding the technical challenges facing the three laboratories. The DOE and its Office of Defense Programs, like the rest of the federal government, are responding to Congress' and the Administration's efforts to reduce government spending and balance the federal budget. With the downsizing and restructuring of the weapons production complex that has already taken place, an increasing proportion of actual nuclear weapons experience resides with the scientists and engineers at the DP laboratories (Figure 3).

\section{The Challenge of Science- Based Certification}

With the cessation of nuclear testing, a new approach is needed for certifying the safety and reliability of U.S. nuclear weapons. The DOE and the DP laboratories have developed a proactive and responsive strategy-science-based stockpile stewardship and management. Instead of using nuclear testing to certify the weapons' safety and performance, we will rely on an improved understanding of the fundamental science underlying nuclear weapons and their operation. Instead of

\section{U.S. Nuclear Policy in the Post-Celd War Era}

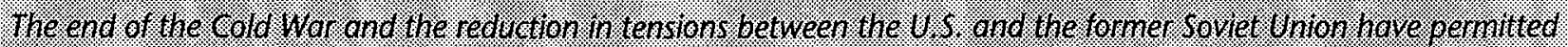

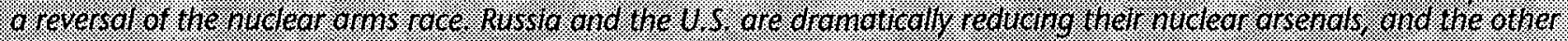

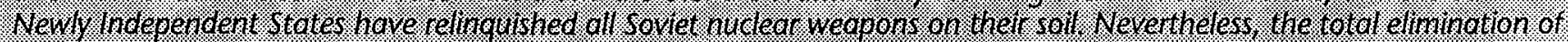

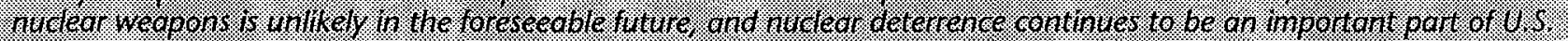

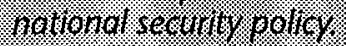

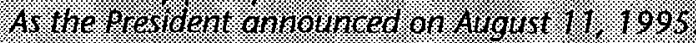

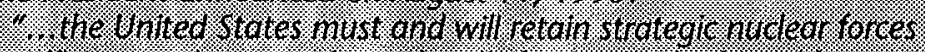

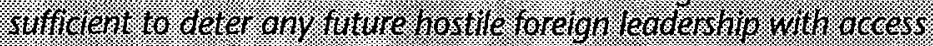

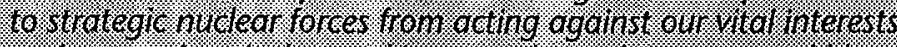

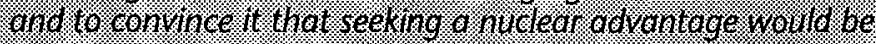

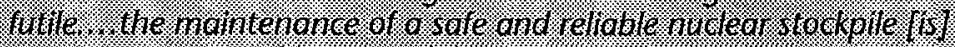

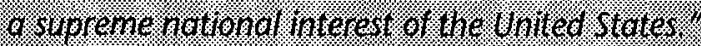

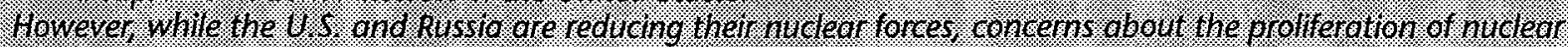

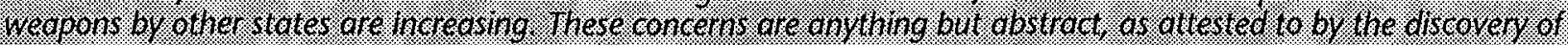

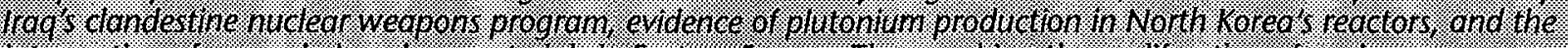

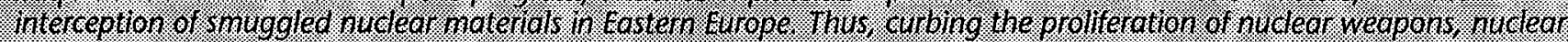

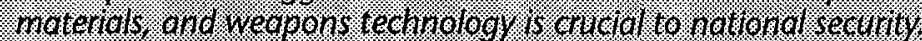

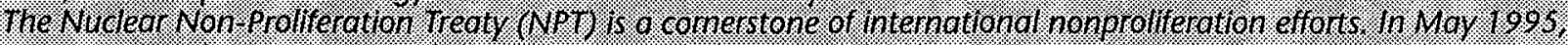

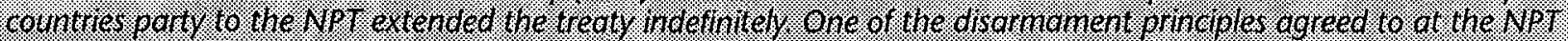

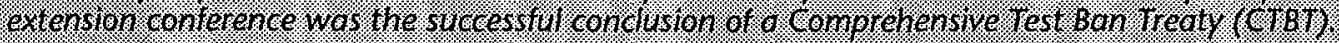

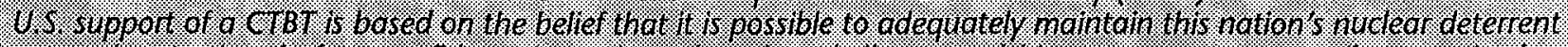

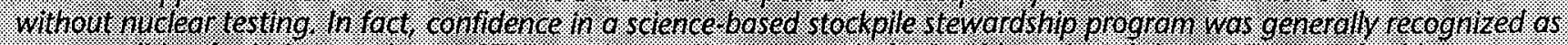

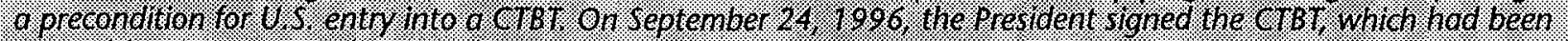

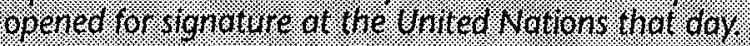


introducing new-design weapons into the stockpile to replace older systems, we will apply firstprinciples understanding to predict aging-related changes in existing weapons, to design fixes and retrofits as necessary, and to certify the weapons' continued safety and reliability.

Acquiring this fundamental knowledge is a formidable task, encompassing many areas of sciencc and technology and requiring enhanced experimental and computational capabilities. We need a detailed understanding, on the one hand, of physical phenomena that occur at extreme pressures and temperatures and last only a fraction of a second. On the other hand, we must understand the subtle processes that develop at ambient conditions over many years. We must fully understand these complex, interrelated phenomena and processes so that we can accurately model them with numerical simulations and predict their occurrence and effects.

The ability to predict the effects of aging-related changes in weapon materials and weapon components is essential. Nuclear weapons are not static objects. They contain radioactive materials that decay. Being radioactive, these materials have limited lifetimes. This is particularly true for tritium, which has a 12.5-ycar half-lifc. Such limited-life components must be replaced periodically throughout the weapon's lifetime. In addition, radioactive decay produces heat and decay products that cause changes in the radioactive material itself and in adjacent materials. For example, plastics and other organic materials are highly susceptible to heatrelated damage, and many metals become brittle after long exposures to radiation. As the weapons age, changes occur, and these changes may, singly or in combination, affect weapon safety and reliability.

The current U.S. nuclear stockpile is older than it has ever been before, and weapons in the enduring stockpile will age well beyond their original design lifetime. We are entering uncharted territory as weapons in the stockpile age bcyond our base of experience. No matter how carefully we prepare now, we know we will have to dcal with new and unanticipated problems that are beyond our experience base.

\section{The Challenge of Nuclear Readiness}

The DOE is also charged with "preserving the core intellectual and technical competencies of the U.S. in nuclear weapons" (Public Law

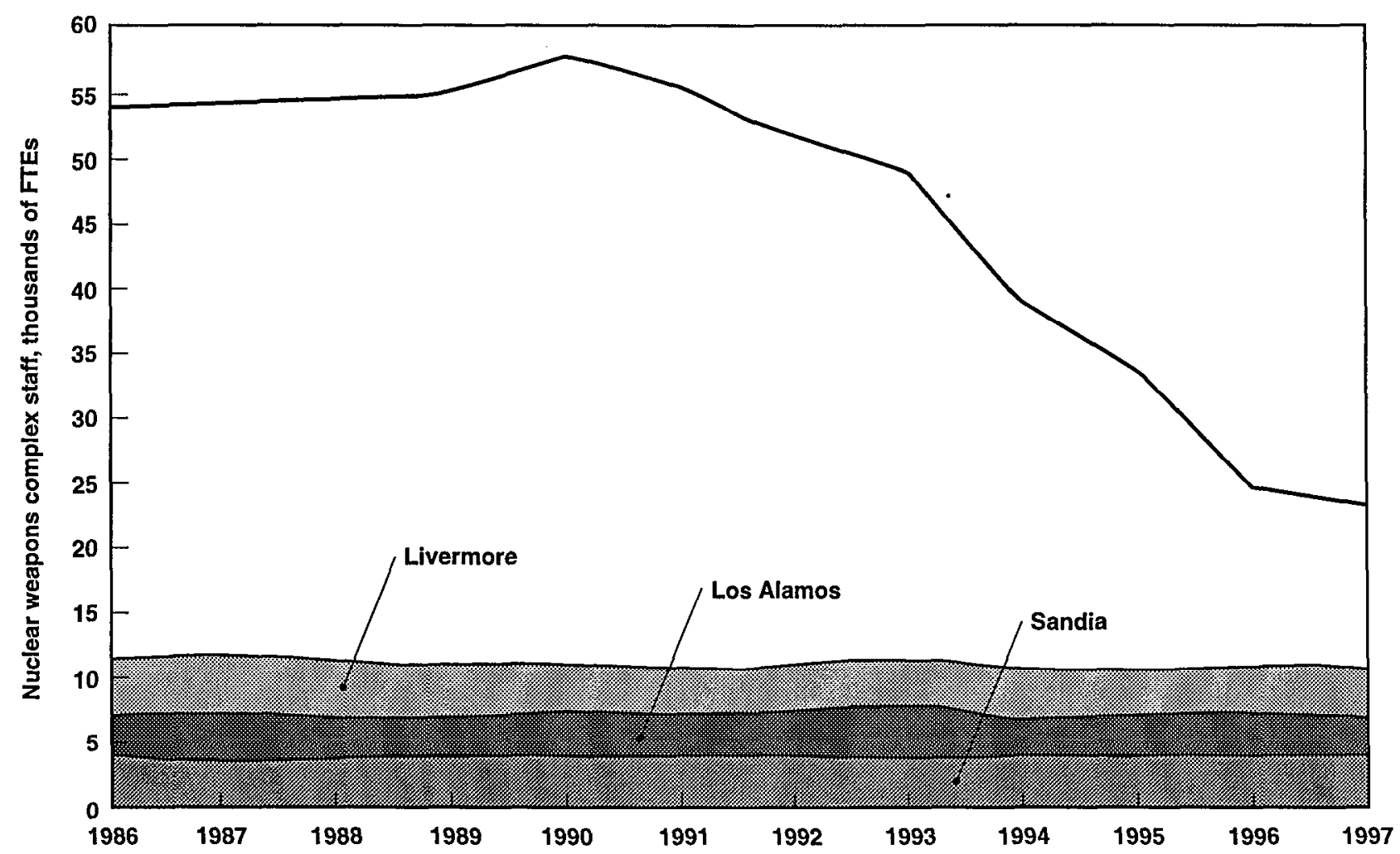

Figure 3. With the downsizing and restructuring of the U.S. nuclear weapons complex over the past several years, an increasing proportion of the nation's nuclear weapons expertise and experience resides at the $D P$ laboratories. 


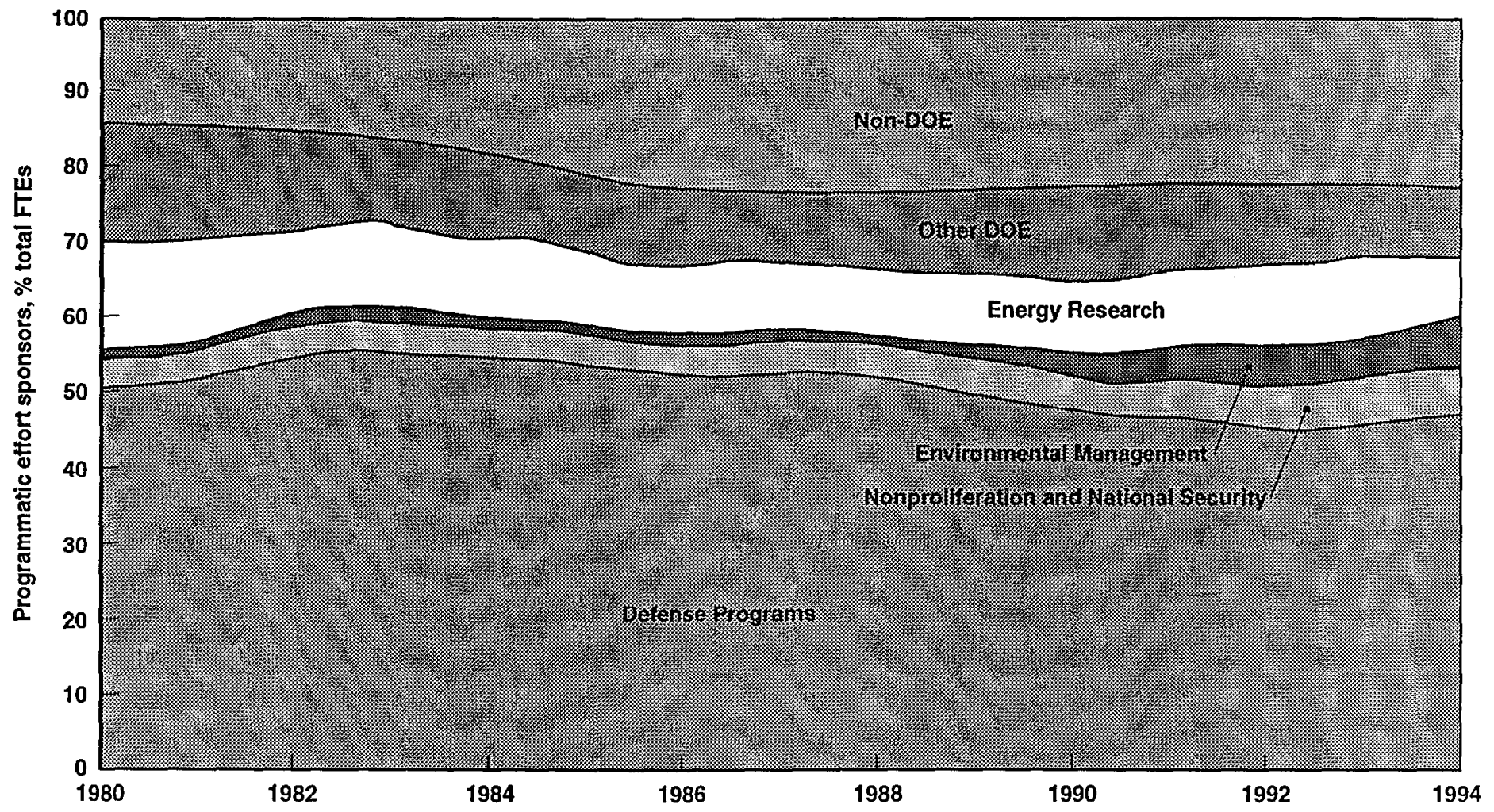

Figure 4. The DP laboratories have pursued multiple programs for many years, to the mutual benefit of their national security mission and their other programs. Shown here is the relative division of effort among various DOE and non-DOE sponsors.

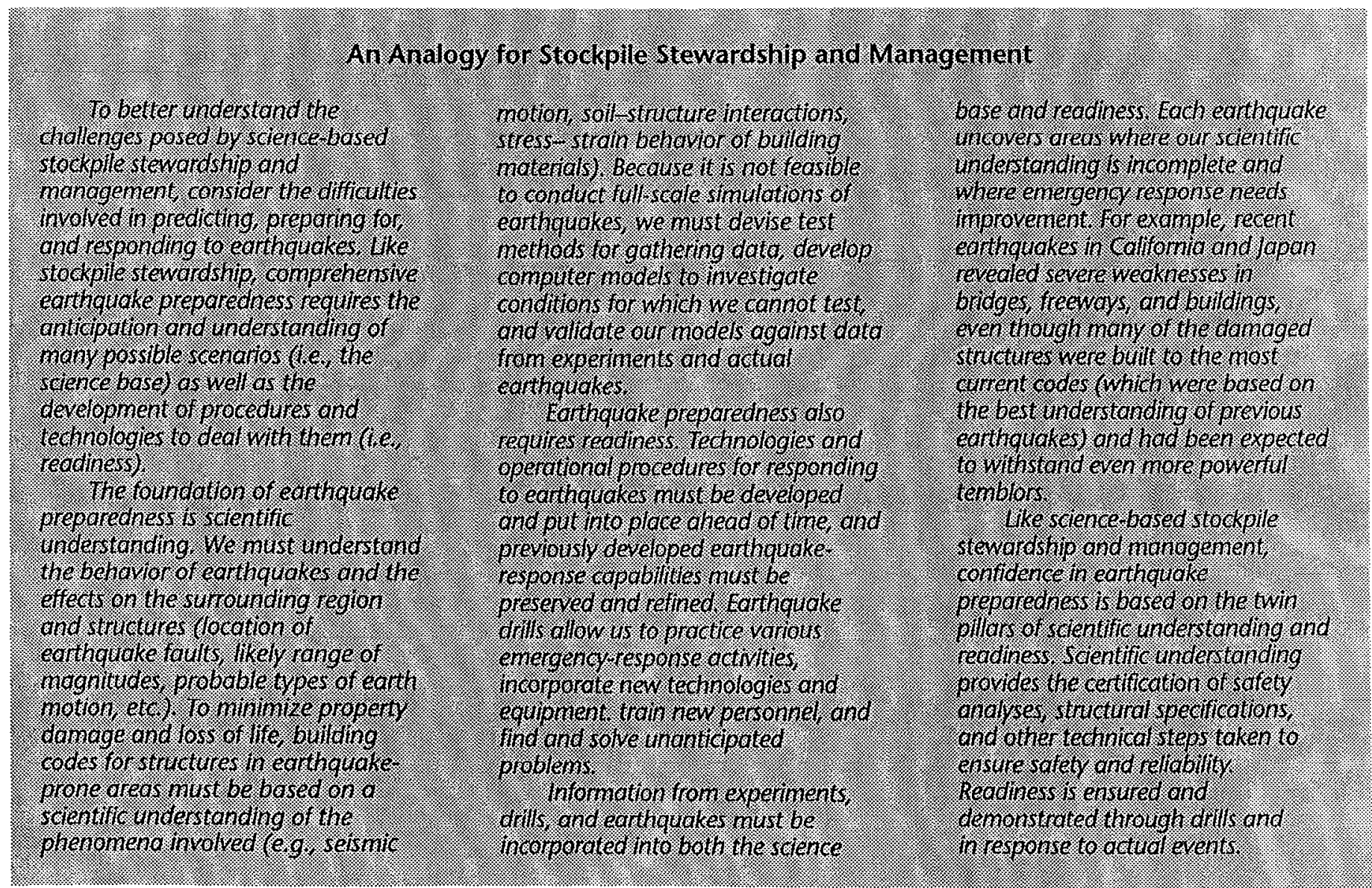


103-160; November 30, 1993).

Maintaining readiness-in nuclear testing, weapons design, and weapons manufacturing-involves more than archiving current capabilities and collective nuclear memory. At the very least, we must maintain capabilities for producing and replacing limited-life components. In addition, sometime in the future, a decision may be made to resume nuclear testing or to produce new-design weapons.

In both cases, we will need to do more than activate past processes and capabilities. Some past processes and capabilities will not be available; for example, previously used materials may be unavailable, and older processes may not meet current environment, safety, and health (ES\&H) requirements. We will need new materials, processes, and capabilities, and thus we must be able to take full advantage of the scientific and technological progress made between now and then.

How can the DP laboratories maintain state-of-the-art readiness for activities that cannot be carried out at the present time? The solution to this readiness problem lies in the multidisciplinary character of nuclear weapons science and technology and in the multiprogram nature of the DP laboratories.
Indeed, the DP laboratories have pursued multiple programs for many years, to the mutual benefit of their national security mission and their other programs (Figure 4).

The multiprogram character of the DP laboratories enables them to tackle non-nuclear-weapons problems requiring groundbreaking advances in scientific and technical areas related to their nuclear weapons mission. By meeting their readiness mandate while solving other nationally important problems, they provide maximum return to the nation on the investments made in these laboratories. 


\section{Scientific Vitality at the DP Laboratories}

Continued scientific cxcellence in research and development $(\mathrm{R} \& \mathrm{D})$ programs that are nationally important and technically challenging, together with state-of-the-art experimental facilities and capabilities, are key to attracting and retaining a top-quality staff at the DP laboratories. (Table 2 summarizes the educational background of the DP laboratories' scientists and engineers.) The excellence of the scientists and engineers at the DP laboratories is widely recognized. For example, between 1980 and 1995 , researchers at the DP laboratories received $139 R \& D 100$ awards (these awards are given annually by Research Magazine for the 100 most significant technological advances made that year). Indeed, the technical difficulty of the laboratories' national security mission, and in particular the challenge of science-based certification of stockpile safety and reliability, demands a level of scientific excellence and vitality equal to that required for the Manhattan Project and during the Cold War years.
A remarkably effective science and technology infrastructure exists in the U.S., the major components of which are research universities, federal laboratories (including the DP national laboratories), and industry research centers. By working together, the components of this national $R \& D$ infrastructure can maximize the return on the nation's investment in science and technology. As the 1996 report by the Council on Competitiveness states:

"Federal laboratories and other agencies are an enormous reservoir of scientific and engineering expertise. The national laboratories, in particular, are a fundamental part of the nation's R\&D enterprise, and many of their unique user facilities and equipment are essential to university and corporate researchers as well as to the government. The national labs offer a continuity and scale of operation that cannot be matched by any other sector or even by foreign governments. The federal system [of laboratories] makes a decisive contribution to national security, and a number of laboratories have also proved to be very effective collaborators with academia and the private scetor."

Although national debate is continuing as to how best to manage the federal component of this investment in science and technology, several things are clear. First, all components of the R\&D infrastructure are essential. Each one has different responsibilities and a different goal or customer base in the overall $R \& D$ process.

Second, some overlaps in responsibilities and activities are necessary and desirable. For example, basic research is conducted by universities, national laboratories, and industry - but with different emphases. The same is true for technology demonstration and engineering development. These overlaps provide areas for scientific collaboration and cross-calibration of capabilities, which are necessary for maintaining the scientific vitality of the nation's R\&D

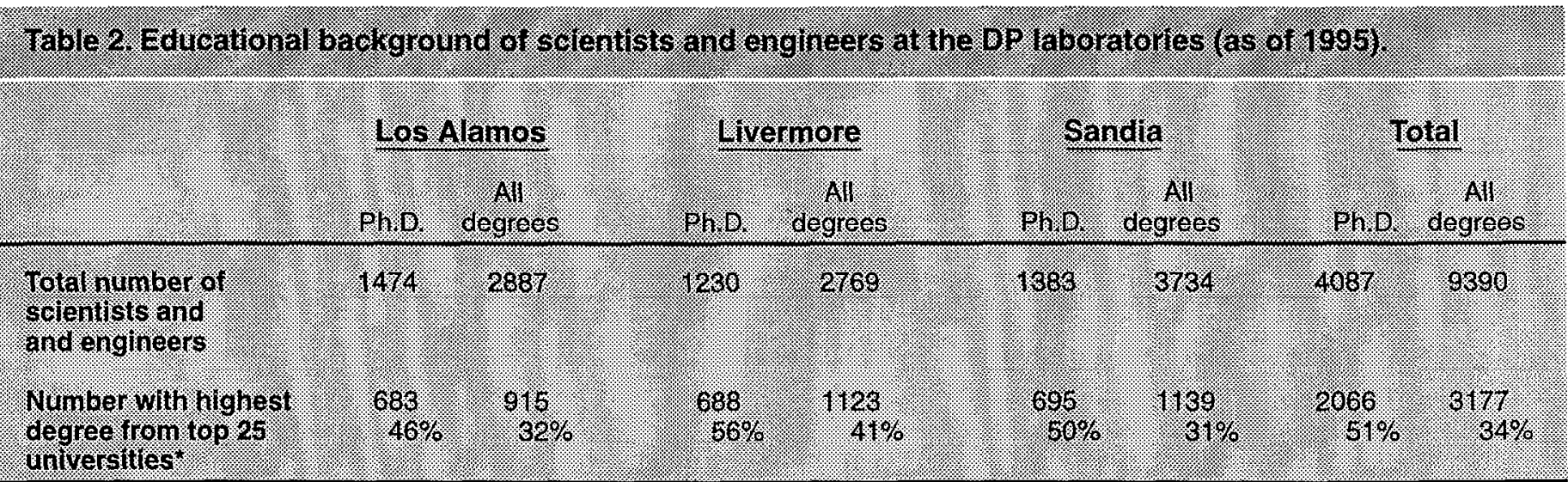

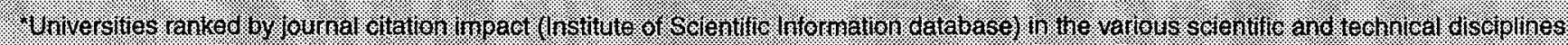
relevant to the or aboratories. 
infrastructure. These overlaps also make it possible for the DP laboratory scientists to recognize the value of science and technology advances made on the "outside" and to adapt them to weapons applications.

Third, collaborations between the DP laboratories and other DOE laboratories, other federal laboratories, universities, and industry engender close technical cooperation and synergy. These collaborations help all involved parties-the DP laboratories and the other institutions - get the most leverage from their R\&D funds, facilities, and capabilities.

The Los Alamos, Livermore, and Sandia laboratories are closely linked by their national security mission and, as such, form an integrated $R \& D$ complex. Together, they have primary responsibility for ensuring the safety and reliability of the nation's nuclear weapons-they "own" the implementation of sciencebased stockpile stewardship.

These DP laboratories have common capabilities in critical core areas as well as individual specialties in various supporting technologies and certain unique facilities. They coordinate their efforts, with each laboratory tackling different pieces of an integrated program and different laboratories pursuing different approaches to a common problem. This combination of overlap and specialization ensures the wide range of capabilities required for science-based stockpile stewardship and makes for cost-effective use of major experimental facilities.

Partnerships with the wider scientific community enhance the DP laboratories' ability to address the challenge of science-based stockpile stewardship and meet their national security responsibilities. In particular, to be on the leading edge in science, the laboratories must be connected with the academic community. Likewise, to be on the leading edge in technology, the laboratories must be connected with industry.

These essential ties were recognized when Los Alamos,

\section{The National Seience and Teehnology Infrastructure}

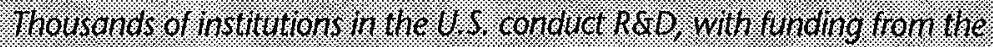

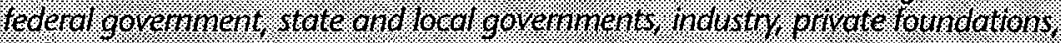
colleges ond whiverities, and other sourges.

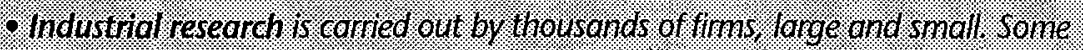

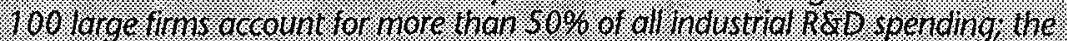

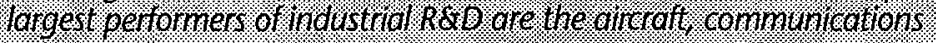

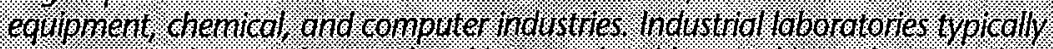

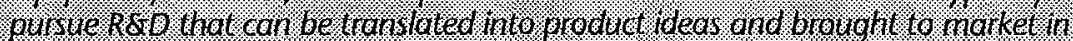
Wo. 20 threentears.

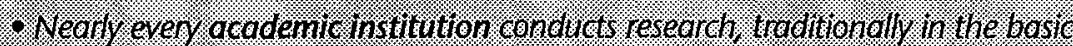

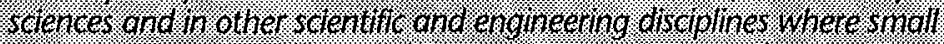

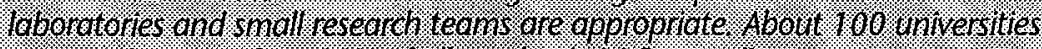

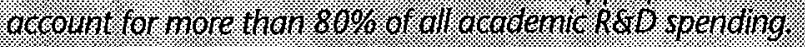

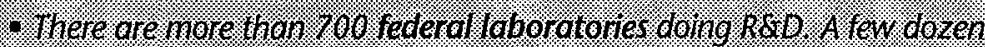

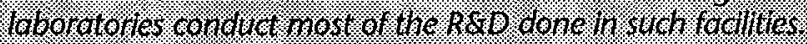

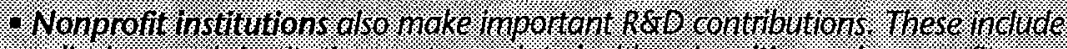
medical researeh institutions hot assoelated with iniversities and nonproft research orgarizations such as Battelle Memonal instivte, Southwest Researeh institute ond others.

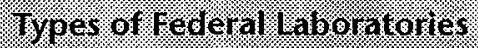

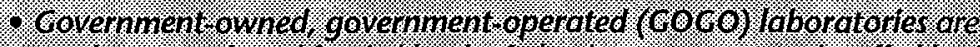
owned operated and funded by the federal govemment and stofted by tederal

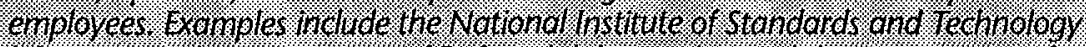
laboratories, the Beportment of Defenses laboratores: and the Department of ighrultures regional laborotortes

- Government owned contractor-operator (COCO) Ioboratortes ore owhed and turded by the federal government ordd operd ted and stotred by. phivate contractors. The contractor may be a profitrnaking tim a nomproft

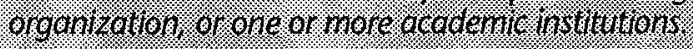

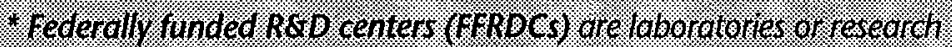
Eenters tumded wholly or substomtiolty by the rederol government Some

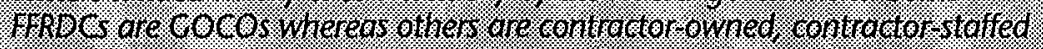

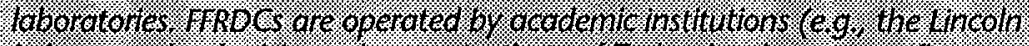

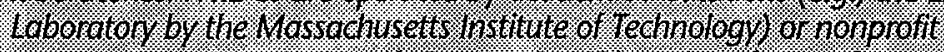

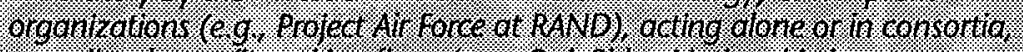
as well as by profitmaking tims (e-9. Oak Ridge National Labaratory. opercted by Lodkheed-Martin Copporation.

- National laboratories are the larges nuttipumpose laboratories of the

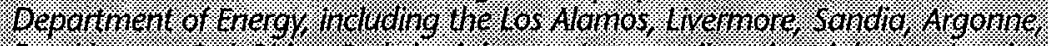
Brokhoven Oak Ritge Berkeley laboratones as well as the idaho National

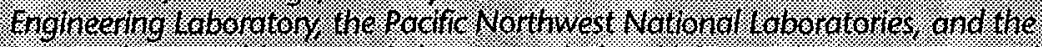
Nattonal Renewable Energy Laboratony. Nationallaborotories ate one type ot IFROC.

4 The three DP laboratories are COCO notional labaratories With hational

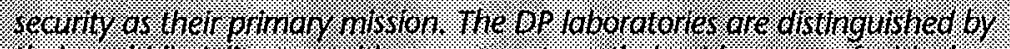
their multissephinary, nuttprogram hature, their Wide ronge of ertical core competencies, their abilty to undertake tong term projects, their trock record in exeuting cutting-edge seenee ond technology, and the unique experimentol focitites thet build and operate: 


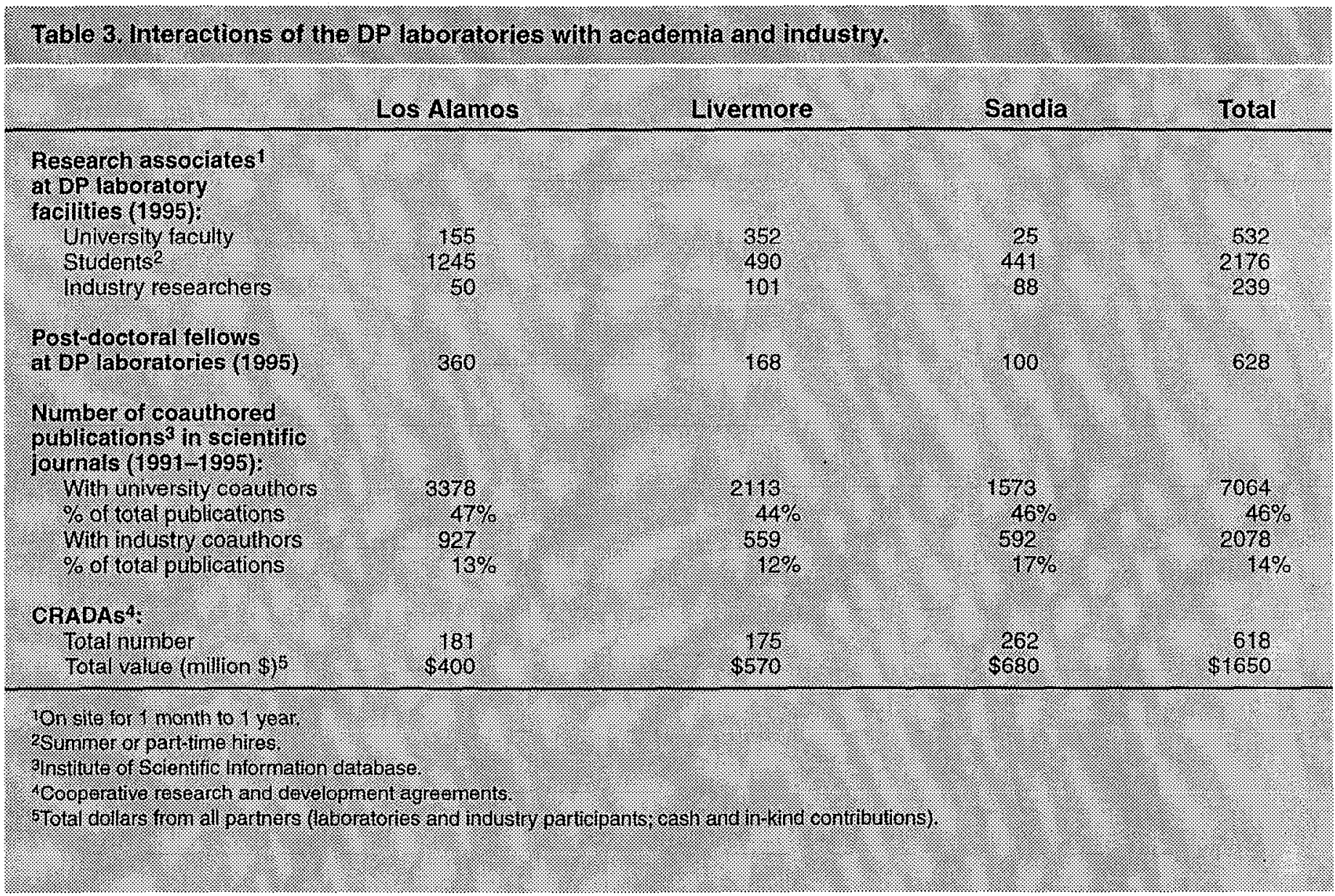

Livermore, and Sandia were founded. Los Alamos and Livermore were created and staffed by academics, and they have been managed since their inception by the University of California. Similarly, Sandia was deliberately staffed and managed by industry, first AT\&T and now Lockheed-Martin (Table 3).

Science-based stockpile stewardship is a "grand challenge" that touches on almost every discipline of science and technology. It cannot be carried out in isolation from the broader scientific and technical community. In addition, in an era of tightly constrained budgets, it is essential that the DP laboratories carry out their mission responsibilities as cost-effectively as possible. Thus, the laboratories must enhance existing partnerships and establish new partnerships with universities, industry, and other research institutions. The inspiration that arises out of associations with university research, the bottom-line pragmatism that develops through interactions with industry, and the intellectual stimulation that accompanies interlaboratory collaborations all play crucial roles in fostering the scientific and technical vitality of the DP laboratories. 


\section{The DP Laboratories: Meeting the Challenge}

THE technical challenge facing the DP laboratories is two-pronged: (1) ensuring the safety and reliability of the enduring U.S. stockpile without nuclear testing and without new-design weapons and (2) sustaining the intellectual and technical capabilities for nuclear testing and new-design weapon production, should they be needed at some future date.

Some of the activities required for maintaining the U.S. stockpile are unique to that mission - in particular, the design and assessment of the nuclear explosive package and work with plutonium - and these activities must be carried out at the DP laboratories within the nuclear weapons program. However, given the multidisciplinary nature of nuclear weapons work, much of the science and engineering and many of the capabilities required for sciencebased stewardship can be developed and

\section{3.}

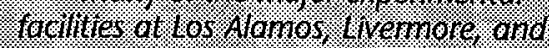

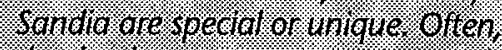
Theodevelopr aent construction and

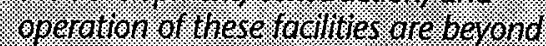

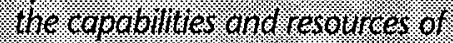
inausth. quiversities ang other phivate iesearch instivitions. The G boratories.

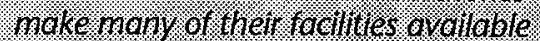
to outside researghers, orten through

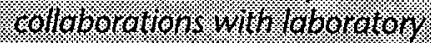

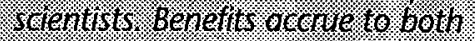

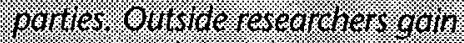

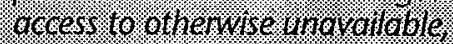

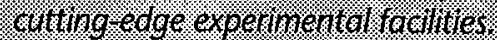

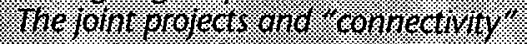
With serentitis trom acadenta.

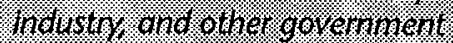

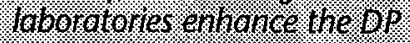

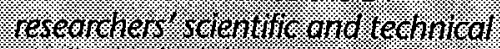

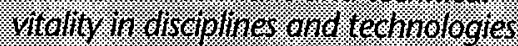
relavant to when national seatrity

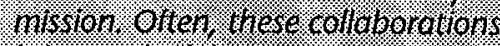

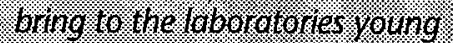

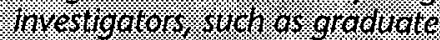

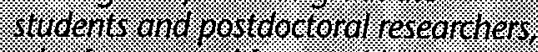

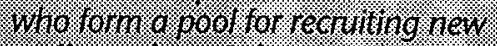

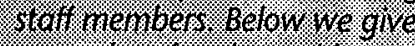

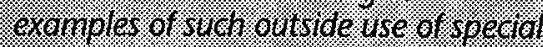

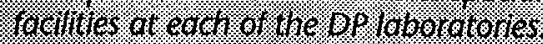

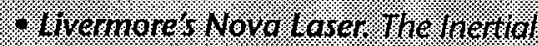

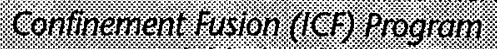

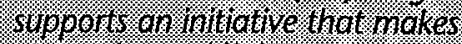

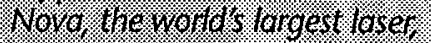

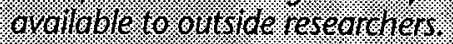

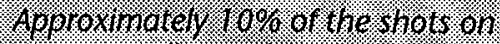

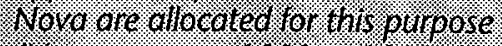

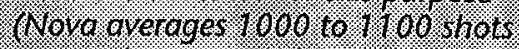

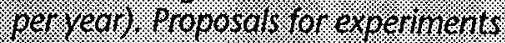
uning vovo orre subpinted for beer.

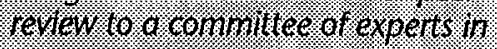

\section{Special Facilities at the DP I I b boratories}

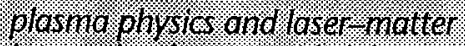
inter action from 0ultside laborateries.

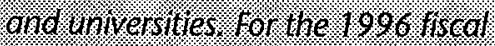

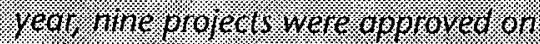

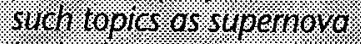

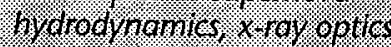

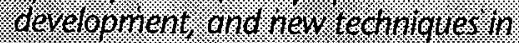

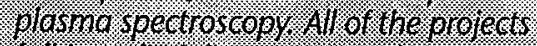
rallinto disciriman greas relevint 10

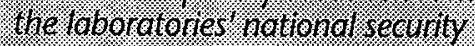
Wisston. As a revult of these ond of ther collaborotions. wore wion $15 \%$ of the

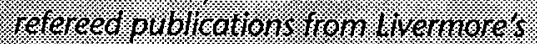

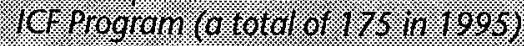

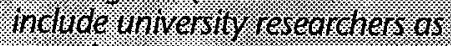
10010101015

\section{- $1.8 \mathrm{~s}$ Alamos Neutron Salenos Genter}

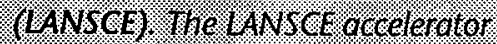

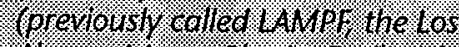

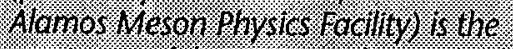

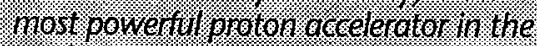

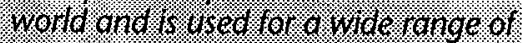

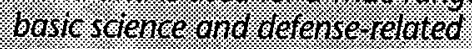

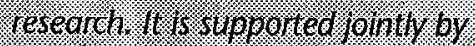

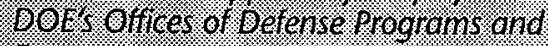

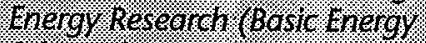

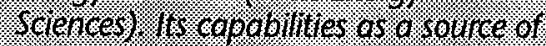
intense orotun and nevtron bearms are

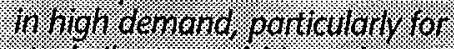

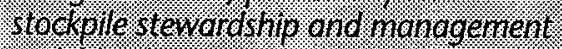

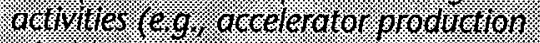

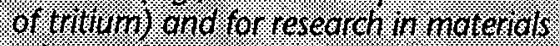

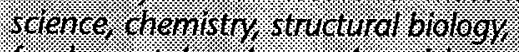

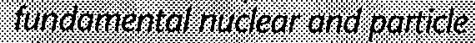
physies and geology . A great

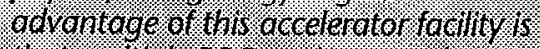

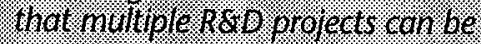

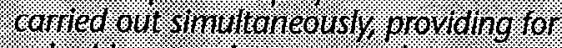
voluoble virergim onnong the discrolines ond peminiting the flow of

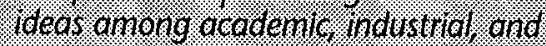

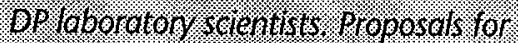

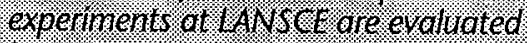

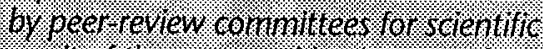

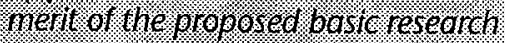

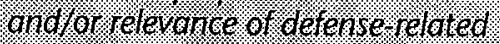

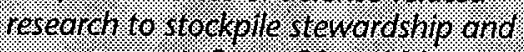

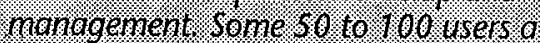
montri condind experiments at: TINSCE.

Sandias Comburton Researdh.

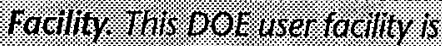

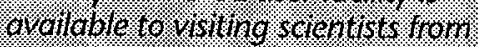
iraustin, univerities, and other

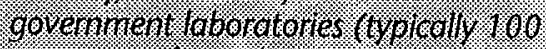

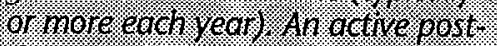

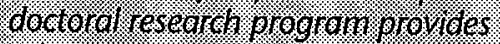

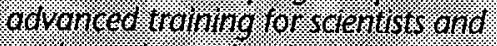

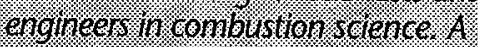

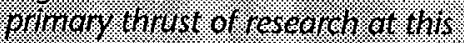
togrty is Gie developnent of advanced

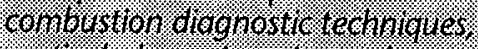

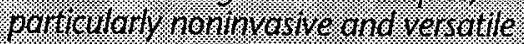

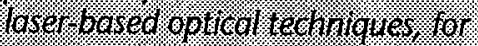
hierswing temperow res chenimat roecter eoncentrations and on her

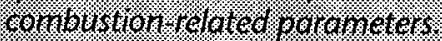
complementivg diagniostic

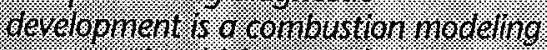

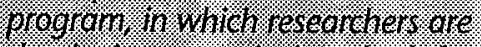

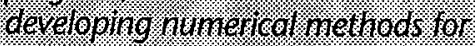

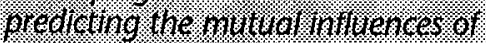

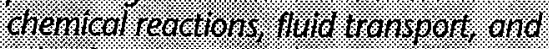

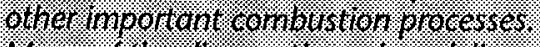
Mony of the diaghostic ond modeling iewhigures developedmo provided.

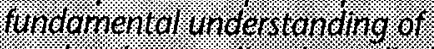

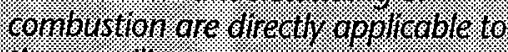

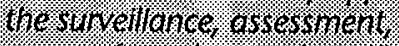

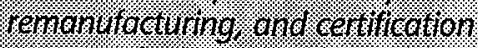

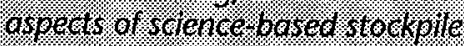
Steworoship. 
advanced through programs addressing other national needs.

The benefits of these non-nuclearweapons programs are multifold.
Because the DP laboratories have developed experimental facilities and capabilities that are unavailable elsewhere (Table 4), they are in a
Table 4. Some of the Specctal or unque experimental acilties at the three DP laboratories:

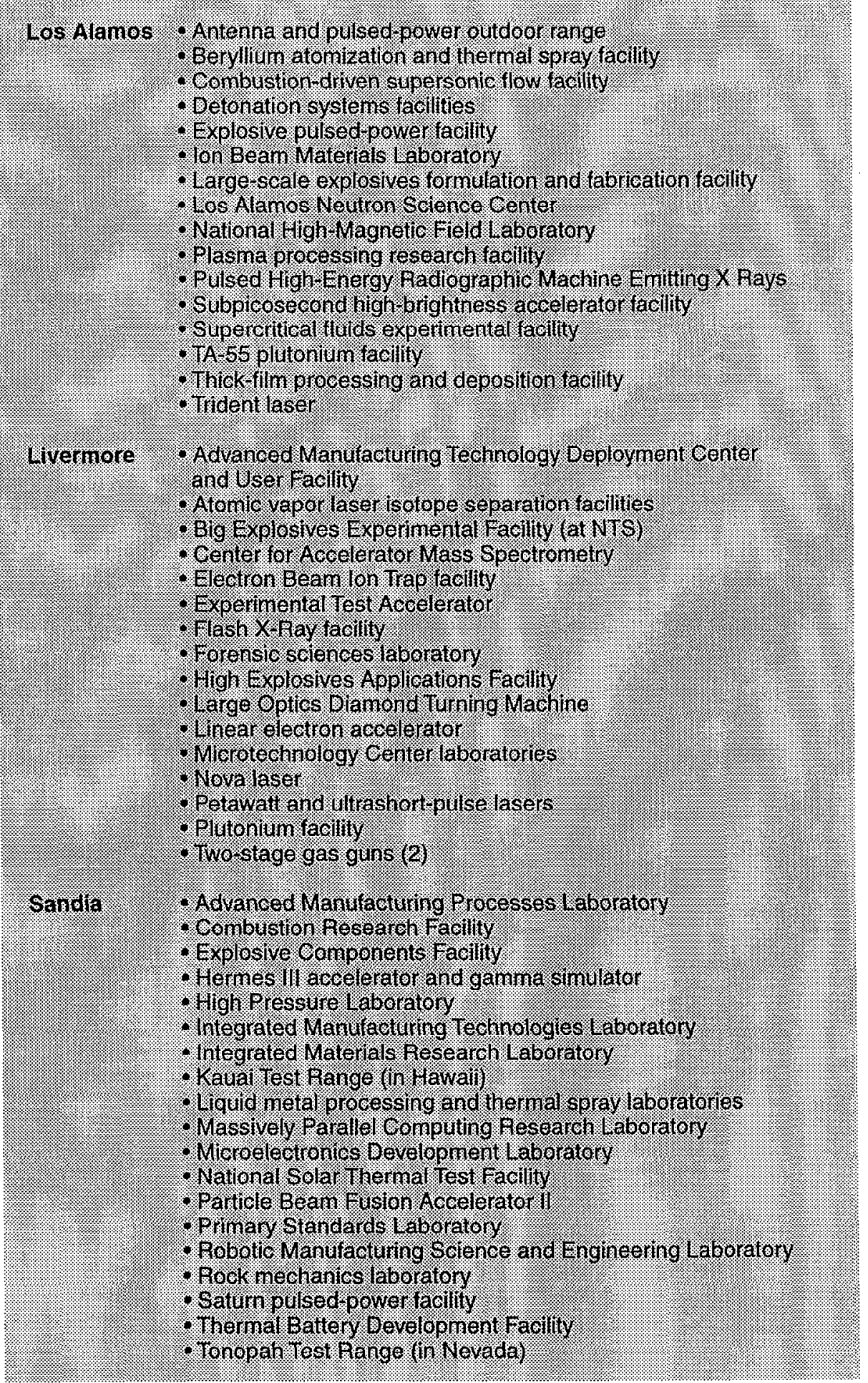

position to make vital and unique contributions to these other programs. Indeed, the spin-outs from the laboratories' weapons work have had a major impact on science and technology in other areas of national importance, including energy supply, environmental preservation, and human health (Table 5).

More important, these other programs help preserve scientific vitality at the DP laboratories, which is essential for meeting their national security responsibilitics. These programs provide weapons scientists with valuable interactions with the wider scientific community, connections that help maintain the critical mass of expertise required for their nuclear weapons work. Through these interactions and collaborations, the unique capabilities and facilities available at other laboratories, universities, and industries can be applied to the DP laboratories' national security mission.

\section{Benefits of Other Programs to the DP Laboratories' National Security Mission}

Through their contacts with the wider scientific community, the DP laboratories have been able to build upon scientific discoveries made by other researchers and to adapt technologies developed on the "outside" to meet weapons program needs. In addition, the use of weapons-related innovations by the DP laboratories' non-weapons programs as well as by industry and the wider scientific community has led to further discoveries that have benefited the nuclear weapons program and enhanced national security.

Work on these other programs and the "spin-ins" and "spin-backs" that result help the DP laboratories carry out their national security mission. Multiprogram work enhances the transfer of ideas, the science and technology base, computational modeling capabilities, etc. As the following examples illustrate, this 
broader and richer portfolio of expertisc cnables the DP laboratories to address nuclear weapons and national security issues more rapidly and effectively than would otherwise be possible (Table 6).

\section{Magnetic Fusion Energy, Strategic Defense, and Advanced Hydrotesting}

The U.S. program in magnetic fusion energy (originally called Project Sherwood) was initiated at the DP laboratories during the early years of the nuclear weapons program.

Weapons scientists were among the first to recognize the potential for harnessing the thermonuclear fusion process for civilian energy production.
The Magnetic Fusion Energy (MFE) Program, now supported by DOE's Office of Energy Research, has had many synergistic couplings to the nuclear weapons program and the laboratories national security work.

For example, the MFE Program developed the technology for producing neutral particle beams for injecting power and particles into magnetically confined fusion plasmas. This technology formed the basis for the Defense Department's effort to develop intense neutral beams for a space-based missile defense system. In particular, the accelerator required to produce the negative ion beam and much of the technology for transporting and neutralizing the beam were adapted from the MFE Program.
The induction linear accelerator was invented as part of the laboratories' Astron Project (one of the first major MFE projects) in controlled thermonuclear fusion and was developed further through application to numerous magnetic fusion experiments. Subsequently, linear accelerators were used to generate powerful microwave beams, using free-electron lasers, for a potential antimissile defense system. Today, linear accelerators are at the heart of Livermore's Flash X-Ray (FXR) facility and Los Alamos' Dual Axis Radiographic Hydrodynamic Test (DARHT) facility, generating the high-energy beams of $x$ rays required for hydrodynamic testing of imploding primaries.

Furndamental Physics Research, Proton Radilography for Advanced Hydrotesting, and Brookhavents Advanced Eradient Synchrotron

Though Inet norn DP?

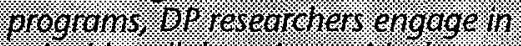

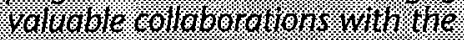

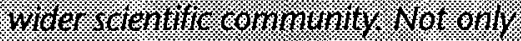

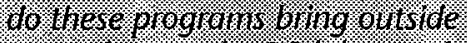

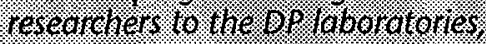
they also ollow Q D r resoorchers to

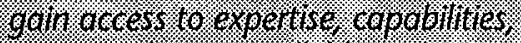

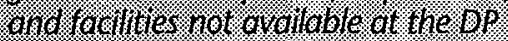
Taboratories This is particularty twe in. nutureor sorence. Whate expenmentation orten requirs.

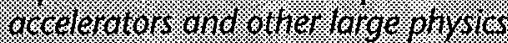
nochings:

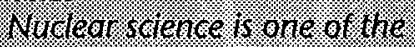

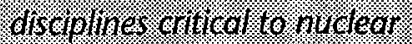

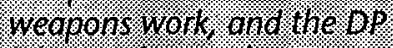

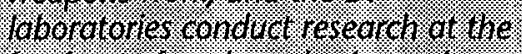

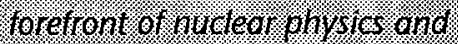

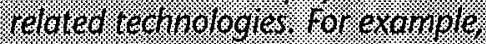

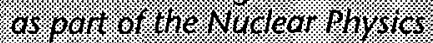

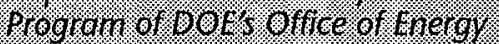

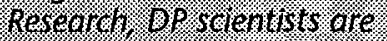
colloboratng with reseorders rom Whuersutes ond ower hationa! taboratortes on oxperiments to probe the tumarmentat now wre ar:

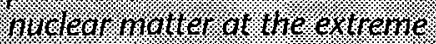
connditions that are neated when

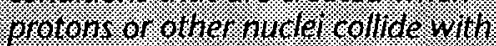

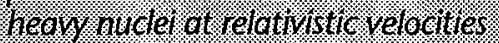

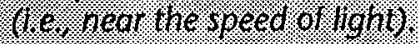

in particular resent experiments.

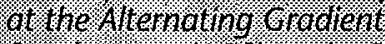

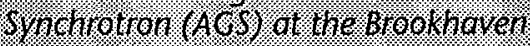

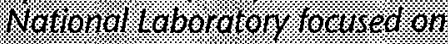

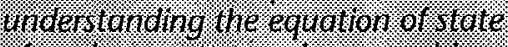

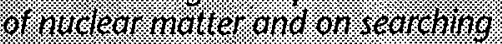

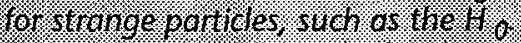

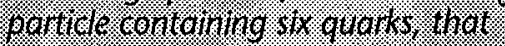

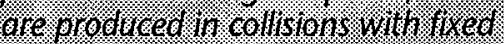
targets at vel nergies. DP. scientists

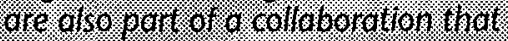

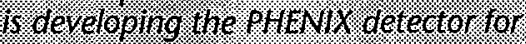

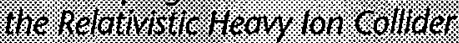
(Ritilc) . He next generation.

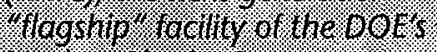

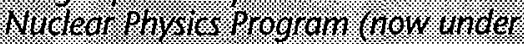
constrigtron an Brooknovent.

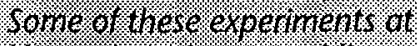

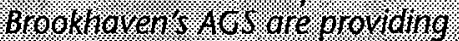
essentist odoto for the stockstle

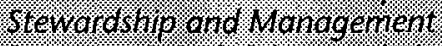

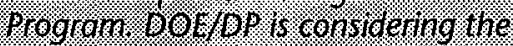

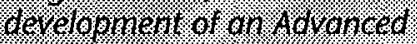

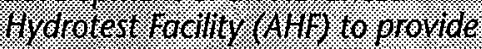

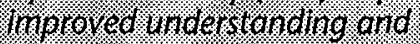
experimentar allutation of the.

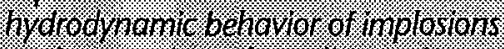

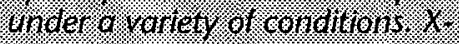
radiography. Is a key experimental tool for ontuming time-dependent: inages of involoding objects in Iaboratory nonnudear experments.

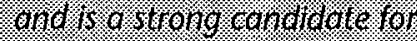

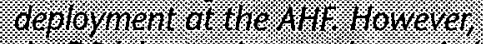

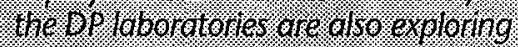
an orlernowve iechingure . protor

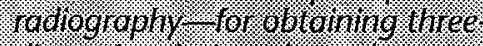

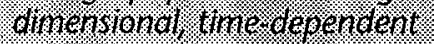
mages with high sporital resolvtion.

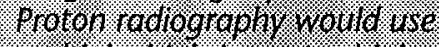

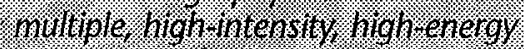

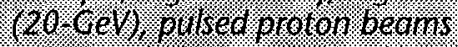
generatcow oy a singre aceelerator

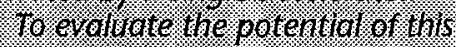

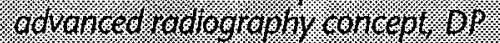

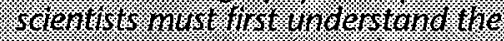

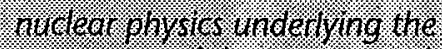
interoction of the Brotons with the

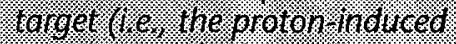

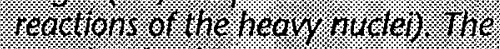

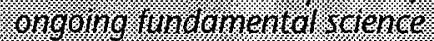

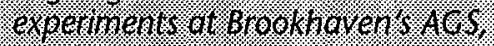

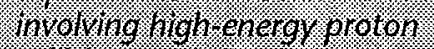

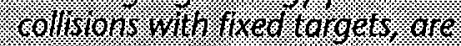

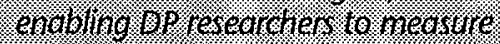

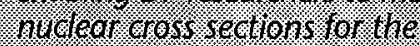

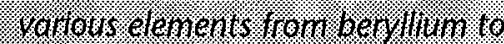

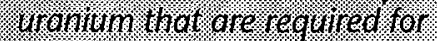

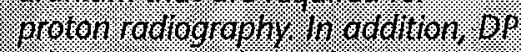

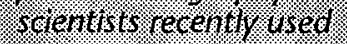

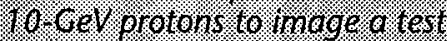

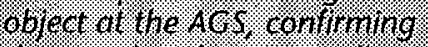
the oromise of proton radiography

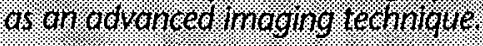


table 5. Highilights of spir outs trom the DP laboratories nuclear Weapons work to other areas of Science and technology.

Spin-out

Weapons program activity

\section{Advanced Manuracturing}

\section{Microelectronics}

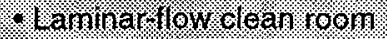

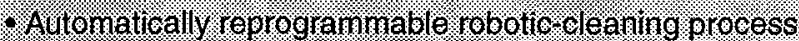
tor in tegrated cirouit boratis

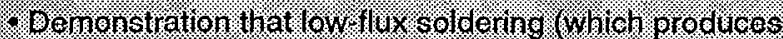

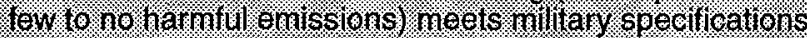
tor printed ed roult boards

\section{Wanulacturing or rocesses}

- Diamondurning and precision machining technologiss tor the optics. semiconductor, and computer industiles

Mearliet shapecasting processes:

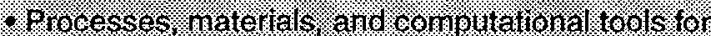

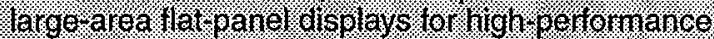

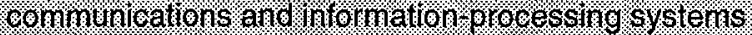

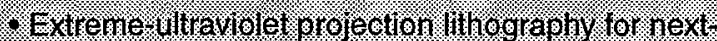
generation mieroereulit fabrication

\section{Advanced materials}

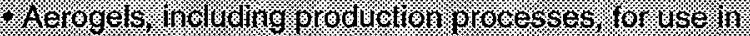
energy storage deviees. nitegrated diefectics, anol water delonization

-optically actwe ceramies tor eptical menory a elices

- Advanced synthiesis ano processing rnetheds. including oninieg and bo onding lee miques:

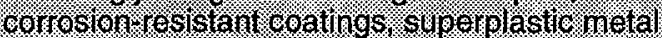

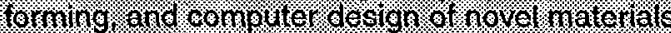

- Ultractean assembly technigues

- Expentise in conputer conntrol of complex systemis. prectsion Tabrication techniques

- Expericheo in devologing and qualifying materials. matcrials. processes. and components tor stingent huclear Weapoons applications

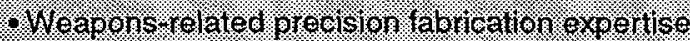

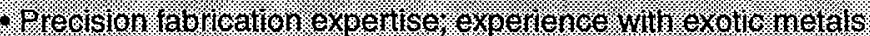

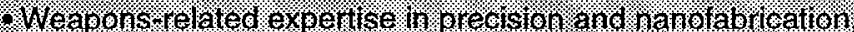

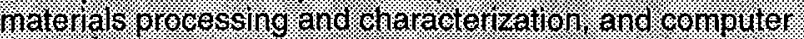
nodoling

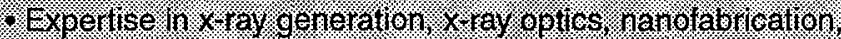
and lasers

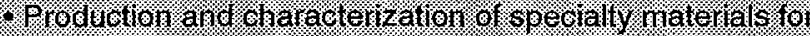

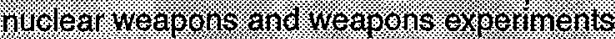

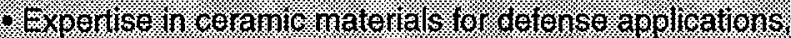

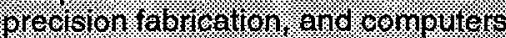

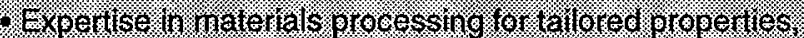

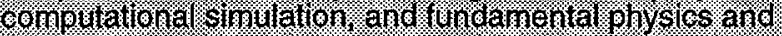
chenistuy:

\section{Energiv}

\section{Fssion energy}

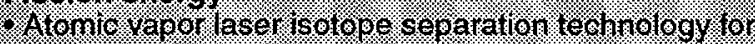

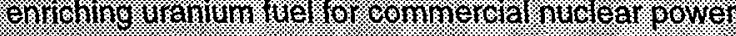
reactors

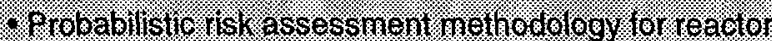

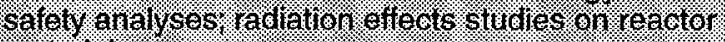
hatertals

\section{Fo.s.11 energy}

- 6.

Yolloshateretoring

- Doetalled understandiling of gasolino contivistion and eminsions fornation processes

\section{Genewablevenergy?}

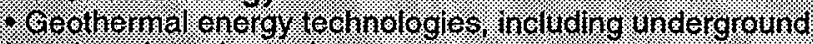

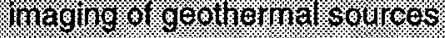

4 Hot dry root concept tor hining and hamessing heat tron ofeer within hio Earth

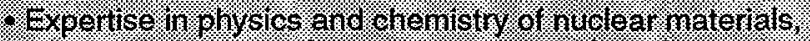

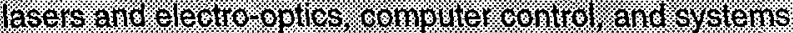
enginering

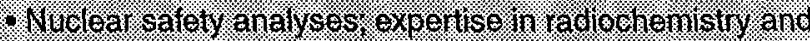
materitals serence.

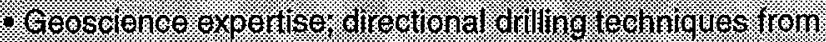
Hoderground nualear resting

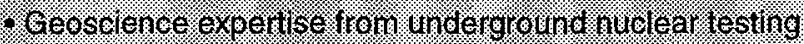

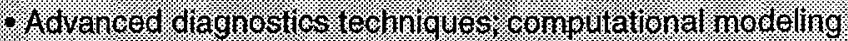
capabilities.

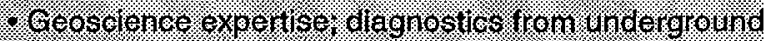
nuclear testing

- DJiling technology font unde ground nuclear testing 
THEle 5. Continiad:

\section{Spin-out}

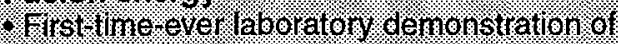

thernienuclea. plasma

\section{Fusion energy}

\section{Weapons program activity}

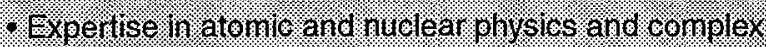
experinentation:

\section{Envronment}

\section{Alinospheric sclence}

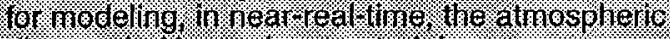
eispersat of hazardous natertals

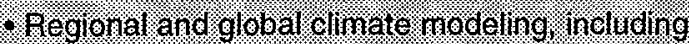
effects of naturaland himan agtivities processes.

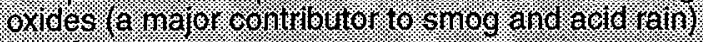
in extauststreatis

\section{Environinental oerediation}

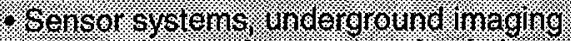
tech Wologres, and converiter sinutations of

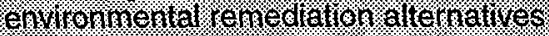

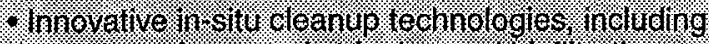

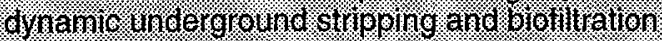

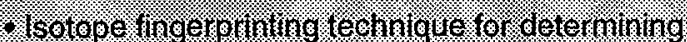

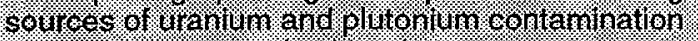

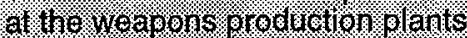

\section{ceosichence}

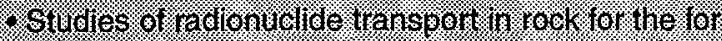

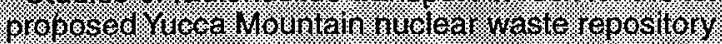

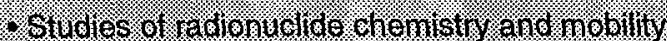

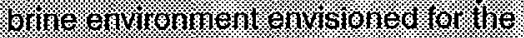
Wasto Solation Pilot pilant

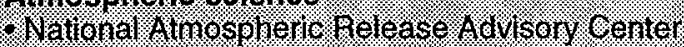

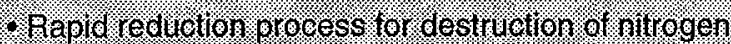

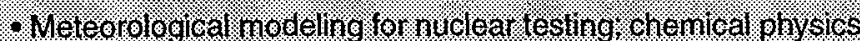
P115.

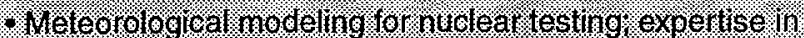

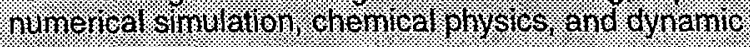

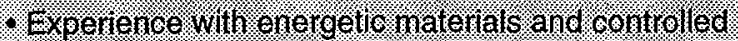
comoustion expertise in chemeal physics

- Instrumentation. geosetence, and computational nod ding

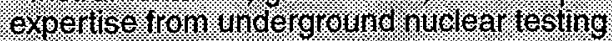

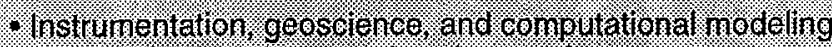

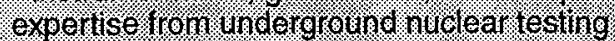

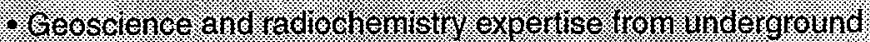
noliveartosting

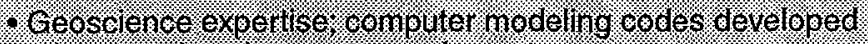

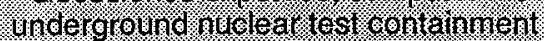

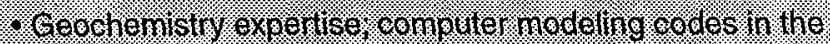

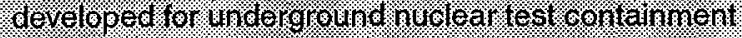

\section{Health}

\section{D10sctence}

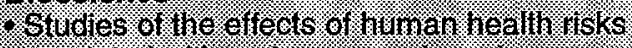

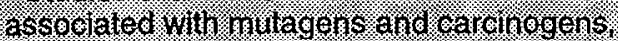

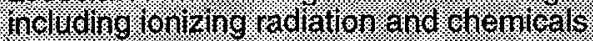

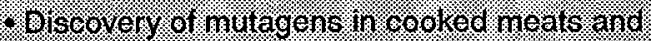

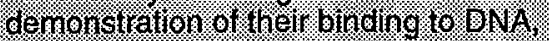

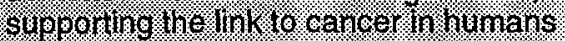

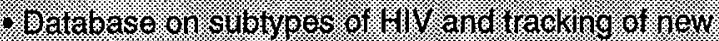

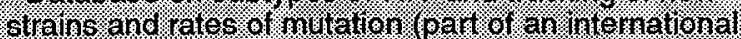
effort io develop ant (I) vacenne)

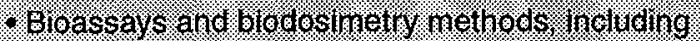

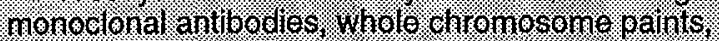

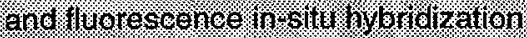

\section{Genomics:}

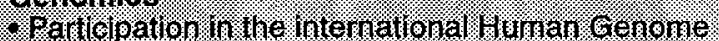

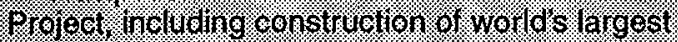

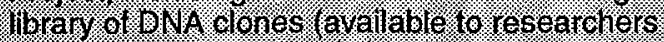
Worlowide) and maps of hiromesomes 16 and 19

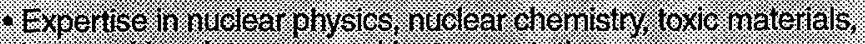
vil rasensitive detectors andir ist unentation

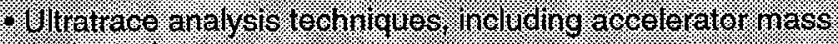
spectronetisy

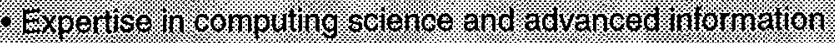
managentit

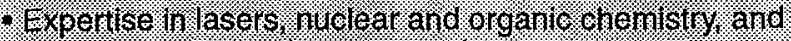

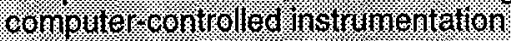

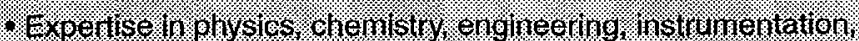
and computational selence 
Table 5. Continued:

\section{Spir-out}

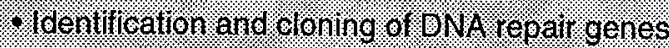

\section{Bioinstrumentation}

- Advanced inaging metrods. including high: ressolution 30 , r ray imaging, high speed 36 image analysis atonice-torce and scamning tumneling Microseopy, and or yo-cry stallography

- Severat generations of altomated high speed flow cytometers

\section{Health-care technologles}

- Digital mammography, including Sothware lor computer assisted examination of na mmegrams

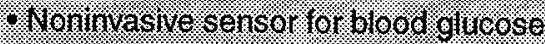

- Techniques tor in vivo maging of the progression and treatment of osteoporosis.

$\checkmark$ Microsurgical tools tor breaking up blood clots and repairing anelingsins

Accurate dose calcailations tor radiation t: Eatment of cancer

\section{Weapons program activity}

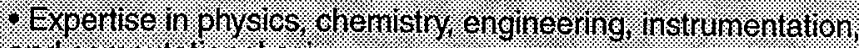
and computational s. $=$ n 100

"Expeniso in nondestrictive evalbation of woapons assentibles. z ray instrimentation. matertal surtace characterization, and complex inage reconstruction

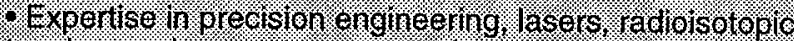
tagging, and coniputer control of compler systems.

- Weapons rest related exper tise in x ray detection. inst umentation, and data analysis te chingues

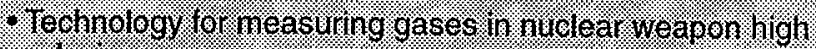
explosives

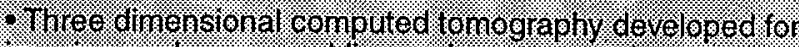
inaging nurlear assentiles and waste contamerc

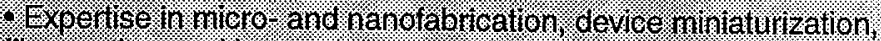
tiber opties, and lasers

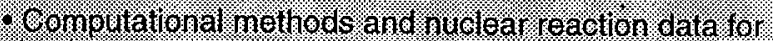
silnulathog radiation trans gort in hue ear. weapons

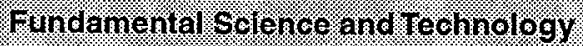

\section{Computing seience}

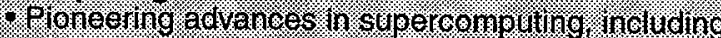
operating systems. data transmission. storage and Tetreval, applieations and modeling codes, and eomputer a fenitectures

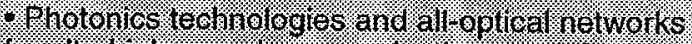

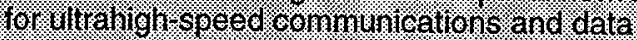
Thanstitission

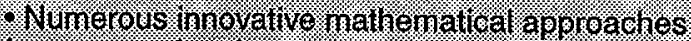

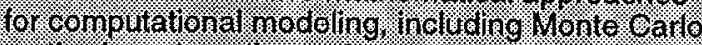
nethods, atitomatie nest generation, nodels or:

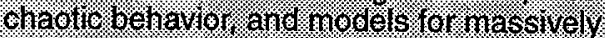
parallel proesessing

- Nimerouls computer codes ano models with

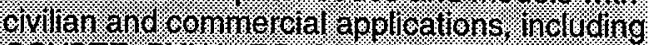

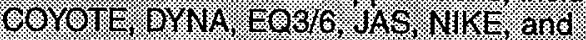
TRAOERB:

\section{Physics.}

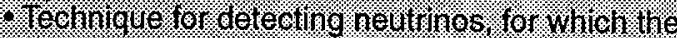
De' researchers were a wan ded the 1995 . Nobel

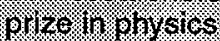

IFist ever metallization of hydrogen. an acconouls himent will najor inolications ror

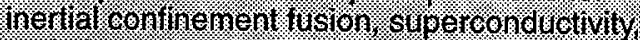

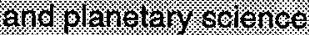

Experimentally validated the on of the funcanientat eloutro weat and electro strong interations between nuchear particles

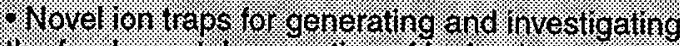

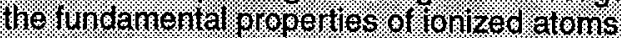

-Weapons development griven ex bentise in all aspects or computers and compuling or screnee

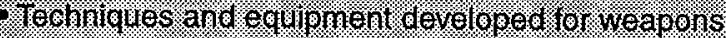

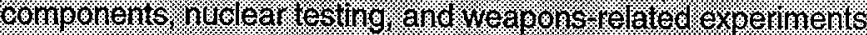

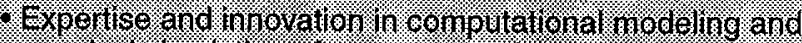

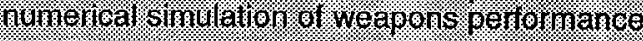

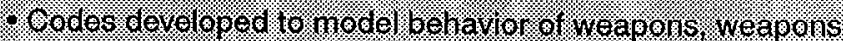
comoonents, target studtures, and weapon residues or a wide

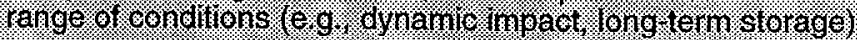

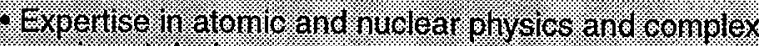
oxpetimentudesigh

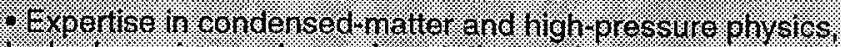

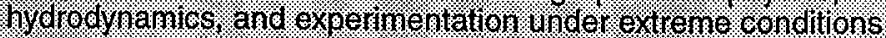

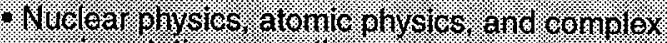
experimentation experise

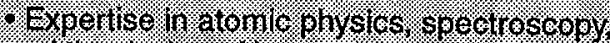

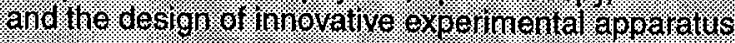


Trable 5. Continued.

\section{Spin-out}

- Experimentally valldated theor, yet the opacity 0 ? stellar matter. Which had a najor impact on the miemoretation of astrophysical on henon thena (c.9. Dutsating statis)

\section{Chemisty and materials, solence}

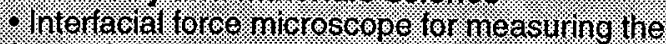

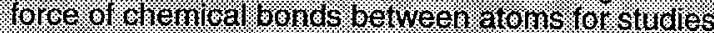

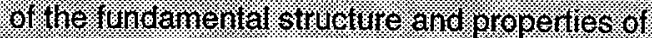
materials

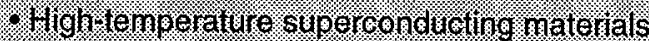

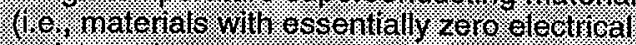
Tesistance)

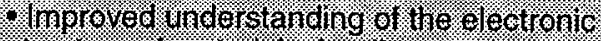

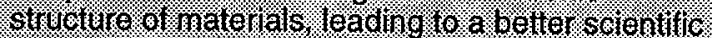
intelp petation of superconatiativity.

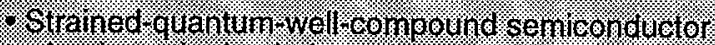

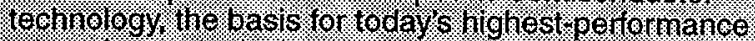
Morodectonia devices

\section{Lasers and accelerations}

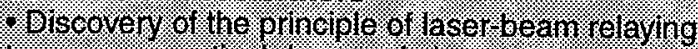

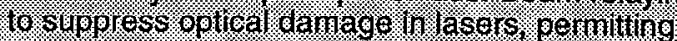
cost teftective ultrahigh orver asers

-Watrous semicondalictor. lasens . or optical connunieations neturorks, nodustral seale:

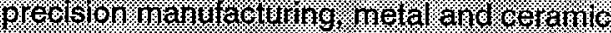

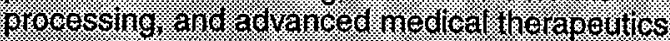

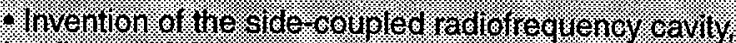

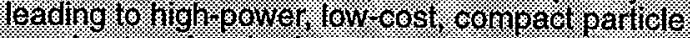

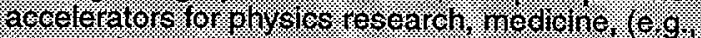

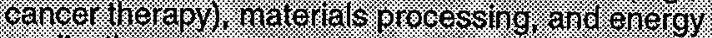
applications

\section{Weapons program activity}

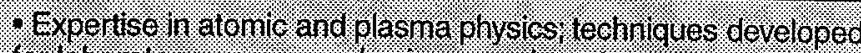
for laboratoy weapons phystos experinents

- Exportisel r materials selence, ehennistry, physics. and

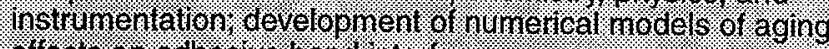

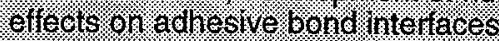

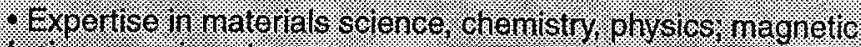
ivision experiments

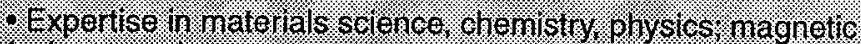
iusion experinents:

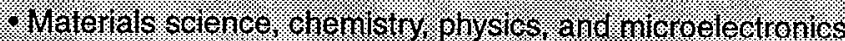

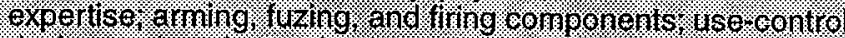

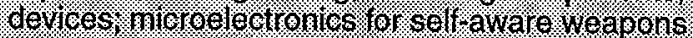

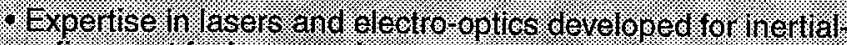
continement fision ex bertments

- Expentise in lasers and electro optics developed tor mentia: continement His son expertmients

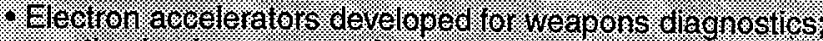

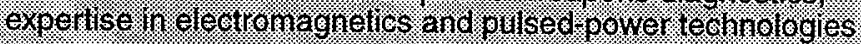

\section{Natonalsecuritu}

\section{Nonnuclear weabons}

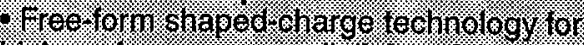

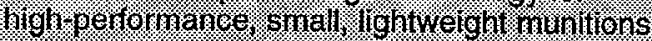

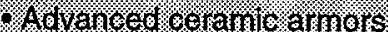

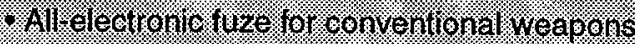

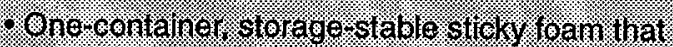

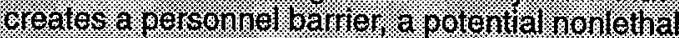

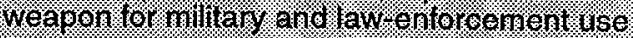

\section{Reconnalssance}

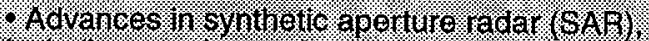

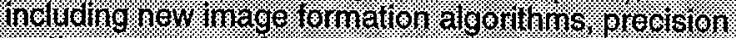
motion connensation, automatic ocusing, and Thol t-speed signal processing

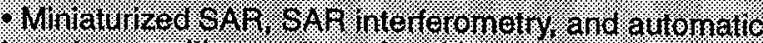

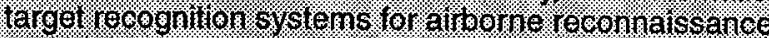

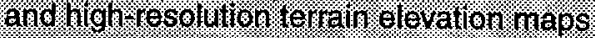

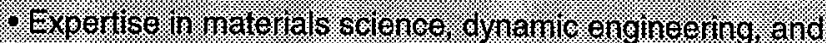

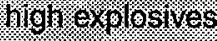

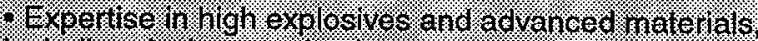

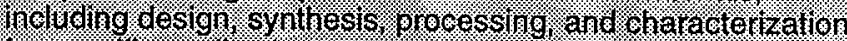
is. ispecific applieations

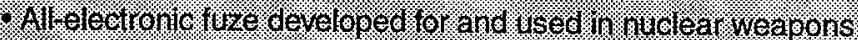

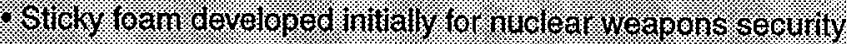

- Data manipuation ard analysis t echineues developed

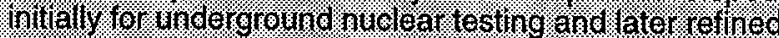

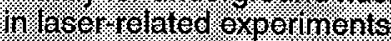

Data manipultion and analy sis techniques developed

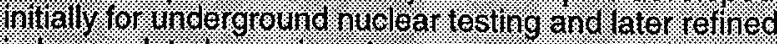
in laser related dexperiments. 


\section{Energy and Environmental Research Computer Codes and Weapons Safety}

Numerical simulation codes are developed and advanced at the DP laboratories in a wide range of projects and applications. A major goal of DP computer modeling efforts is the development of threedimensional, full-system, detailed models of phenomena of interest (Figure 5). For example, programs in oil shale and waste transportation, funded by the DOE's Office of Fossil Energy, supported the initial development of a family of exceptionally powerful and accurate nonlinear solid-mechanics finiteelement codes. Today, these codes are used to simulate weapon crashes, warhead penetration into hardened or underground structures, and weapon manufacturing processes.

The DOE's Offices of Environmental Management and Civilian Radioactive Waste Management funded most of the development of another set of codes through the Waste Isolation Pilot Plant (WIPP) Program as well as much of the development of finiteelement codes for modeling the response of geologic media to the storage of nuclear waste packages for the Yucca Mountain Project. These codes provide a level of speed, detail, complexity, and accuracy unavailable elsewhere. They have evolved into a suite of codes for simulating such complex weapon manufacturing processes as brazing, welding, encapsulation, and glass-tometal bonding.

\section{Deep Borehole Disposition of Plutonium from Dismantled Weapons}

Large quantities of surplus plutonium have resulted from the dismantlement of thousands of nuclear weapons by both the U.S.

(text continued on p. 21)

Table 5. Continued:

\section{Spir -out}

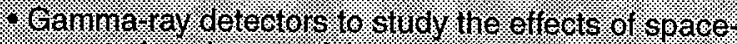
generated muclea mantieles, gamma rays, and : r rays

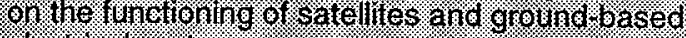
eleetrileal.s.sstems

\section{Strategic nissile deterse}

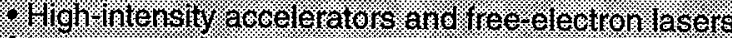

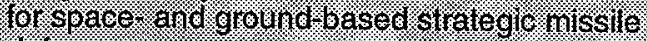
Getense concepts

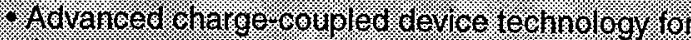
robust SEISSOrs ano instunnentation

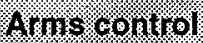

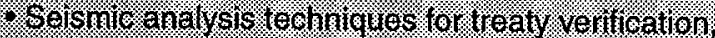

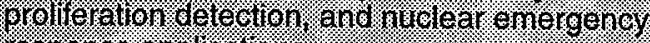
60sponse applications:

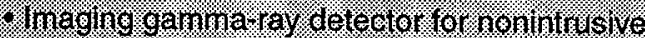

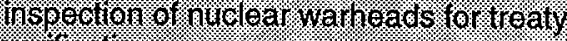
Ventifeation

- Teeninical advice about reaty verifieation

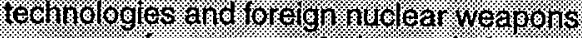
programs tor a ins.contrel hegotiations

\section{Niclear nomproliteratlion}

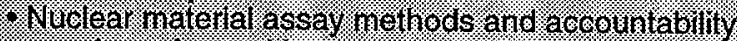

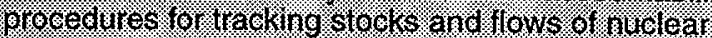
Malentals Wortawade

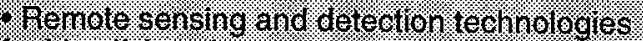

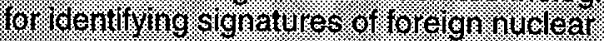

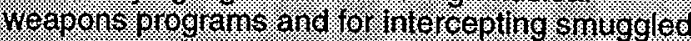
Weaporns and Weapon hiaterial

Neution detectors ror racking and antilbution 6\% surpolis nuclear nialenal

\section{Weapons program activity}

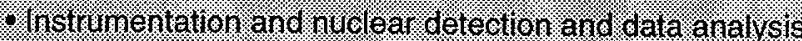

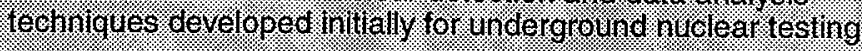

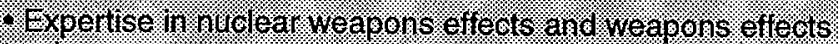
testing

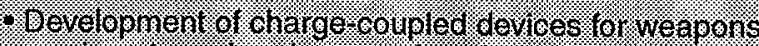
exporinents andumberground nuclear testmg.

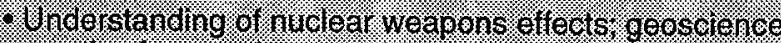

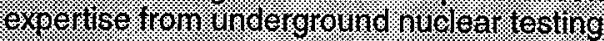

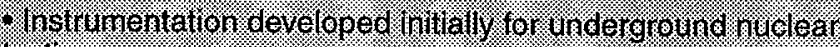
4esting:

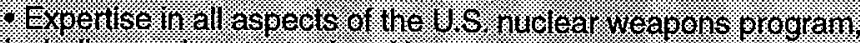

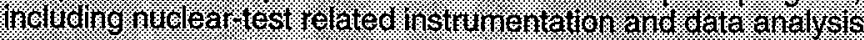

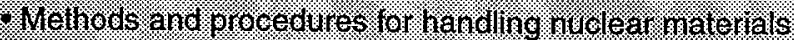

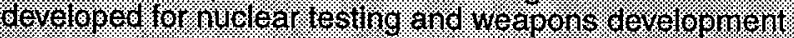

instrumentation, detection, data anatysis, and nuelear.

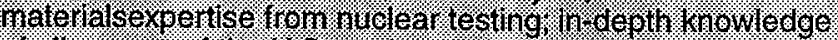

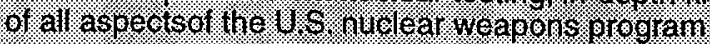

- Weapons and Iest based experisso in nueleat naterials and measuriernents 
Table 6. Highight spin back and spin in contmbitions to the DP laboratories national securtify mission With orgins in the laboratories non-DP work.

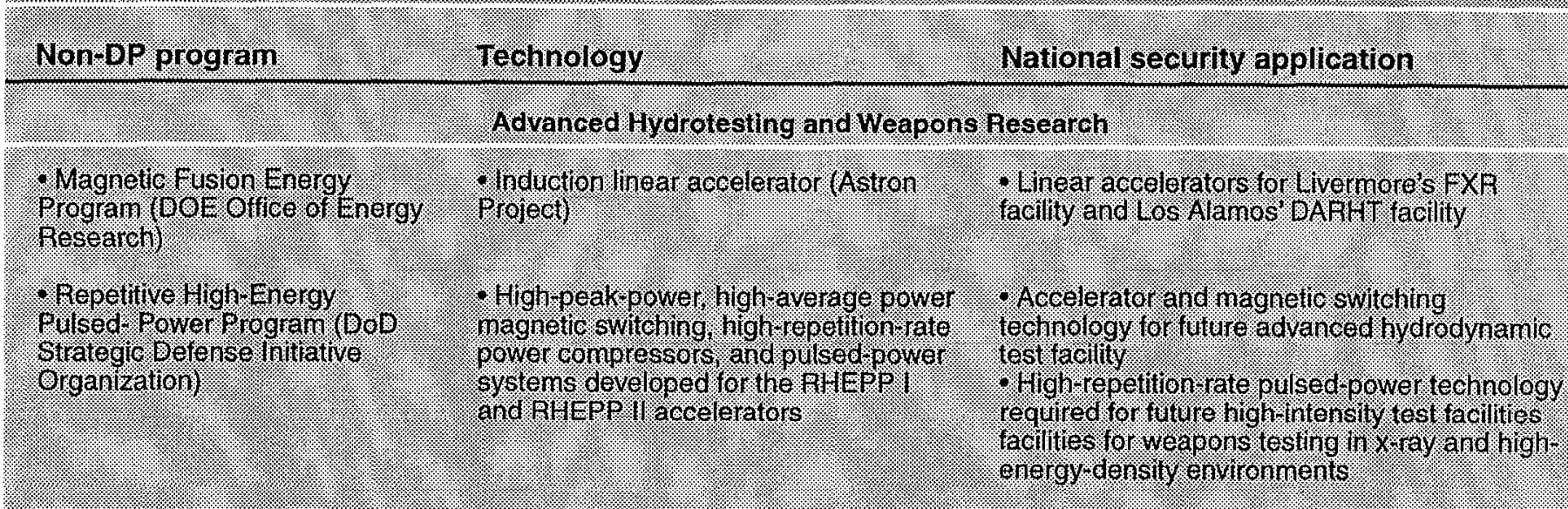

\section{Computationa Simulation}

Oil Shale Progran DOE. Offico of Tossit Energyj)

- National Ethergy Research Subercompliting Center. (B) E E Ofice of Energy Research)

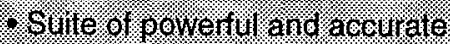
Tansient dianies codes.

- National Storage Laborator interactwo batch gang scheduler for massively paraillel processors: EShet, adaptive nesh tothement techniques

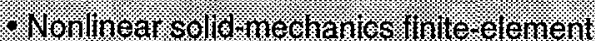
cores rel simulating weapons erashes and

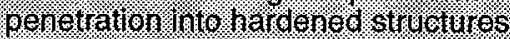

vassively parallel processing expertise high speed neworks, remote eonmunieations, and

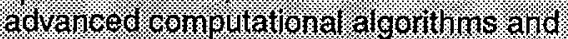

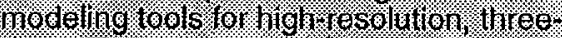
dinensiona simulation. of weabons oentormance

\section{Weapons Manufactiring}

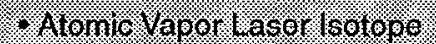
Separation (AVIIIS) Program. DOEE Office or Nirelear Enerigy)

TRepetitive Iigh thengy

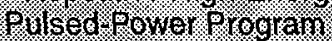

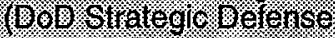
hillative Orgahization)

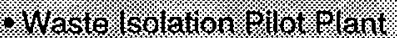

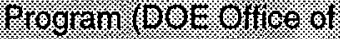

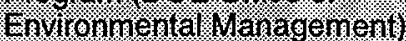

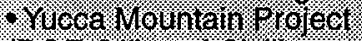
DOOE Office or G vilian

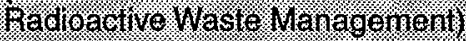

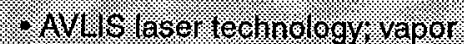
Geposition process; election beam

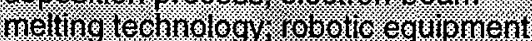

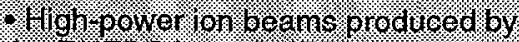
the of w accelerators

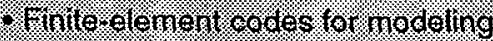
response of geologic nodia to storage ol niverea waste packages

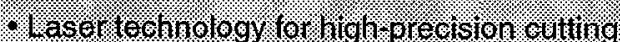

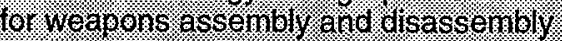

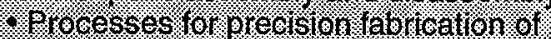

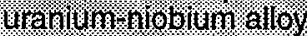

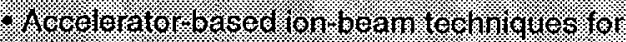
surace treatrnent of hetals, ceranies and 1.0.11710:15

- Finite-element codes tor simulatting we a poras. rianilifactiving on ocesses

\section{Stockpile Maintemance}

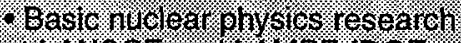

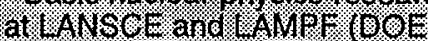

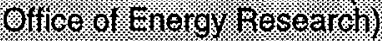

- Derilititatization a ctutites

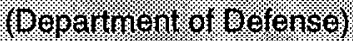

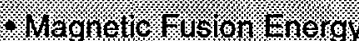

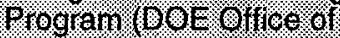
Enorgy (Tesearch)
- Nevituon prodidetions stidies of protor bombardin ent on elements fiom Geryllitin to granitin

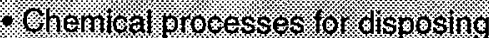
of surpilis explosives an e oropeltants.

- Vetallurgy expoertise ando

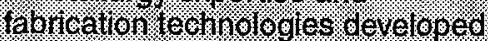
tor the Tore Silpra onkanal

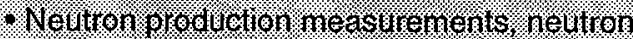

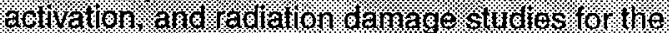

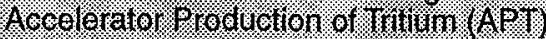
Program

- Nev. less expenstve aroesess ior synthesizing

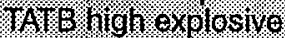

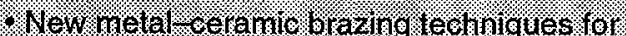

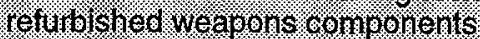




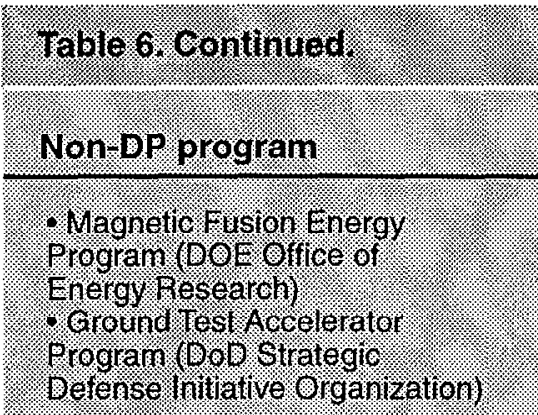

\section{Technology}

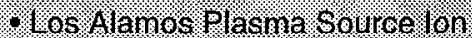

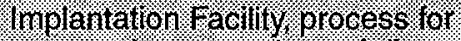
wear reststant ooatings. of diannond:

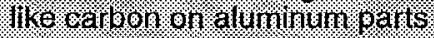

\section{National security application}

- lon implantation and deposition processs for

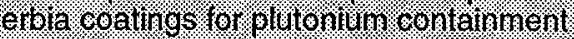
vessels (Weapron plis cruelbles nolds)

\section{Stockolle survelllance}

Materals selenee research

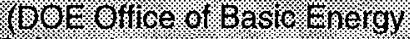
Solence)

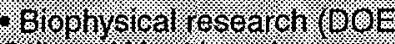
OHilese or Wivalth and

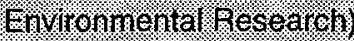

Thtertacial torce migroscope tor studies of Whadamental aspects or adhestre bonding.

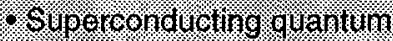

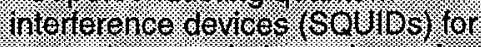

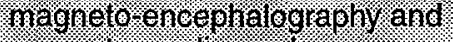

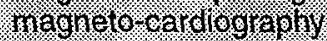

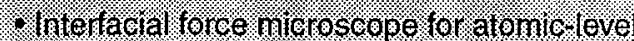
studies of adhesion and bonding in weapons

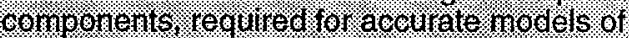
eftects of aging on bonds and hitertaces

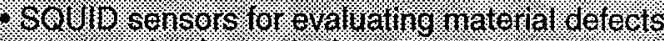
ano corlosion in steckpite weapons

\section{Envionnental Gleanus}

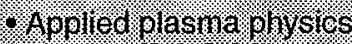

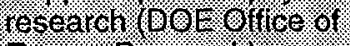

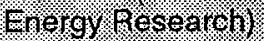

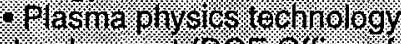

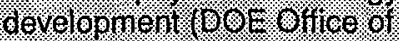
Whironnentat htanagenent

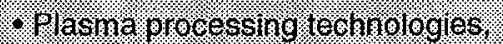
sulet as lange-scale reactive ton etctinge
- Itasma decontanination tectricteres tor

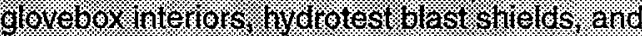

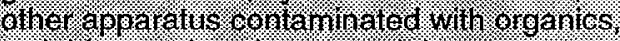
activides. and nuedear naten als

\section{Nulear Wattertals Dispostition}

Sontinental Selentifle orling

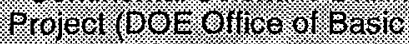
Fiengy Schenes:

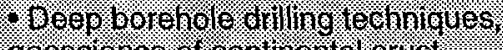
geoscilerlice or continental crust.
Oriling and eanth science oxpertise tor study

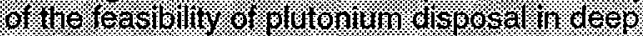
boteholes

\section{Nuclear Test Readiness}

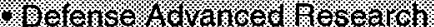

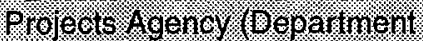
of Defense):
\% holonies tectinology for optieal

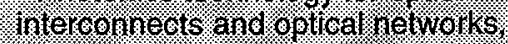
requitired to massively paralle!

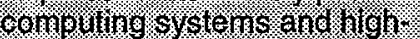

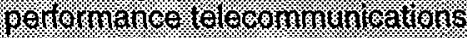

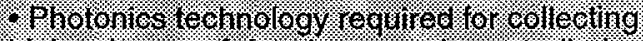

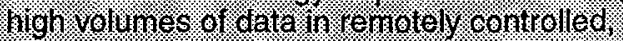
SHor a d uration experinoents

\section{strateglo. Berense}

Wagnetic Ëision. Energy?

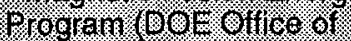
Enorgy Research)

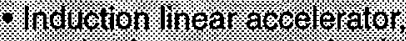

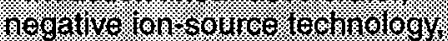
Geami transpont and neutralization technologies

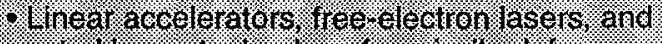

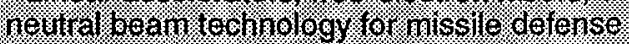
conteepis:

\section{Treaty Verification and A ms Con IIOI}

\section{- Alternative energy projects [DOE E Office of Basio Energy Solences:}

Diophysical iesearch U101: Offies of It tealli and

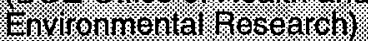

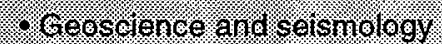
exoertise gained rom hot diy rock

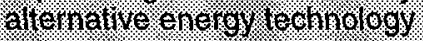

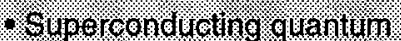

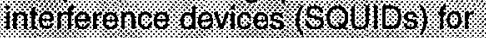
nagneto ence ehalography and magneto carrolograpiny

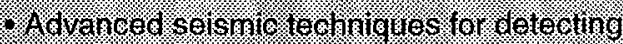
distant anderground midiear lests

- SOUID sensors for exarining storage di uns:

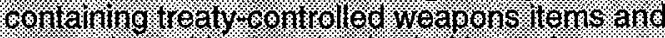

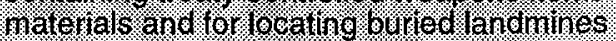
andidnexploded ondrance 


\section{Table 6. Continued.}

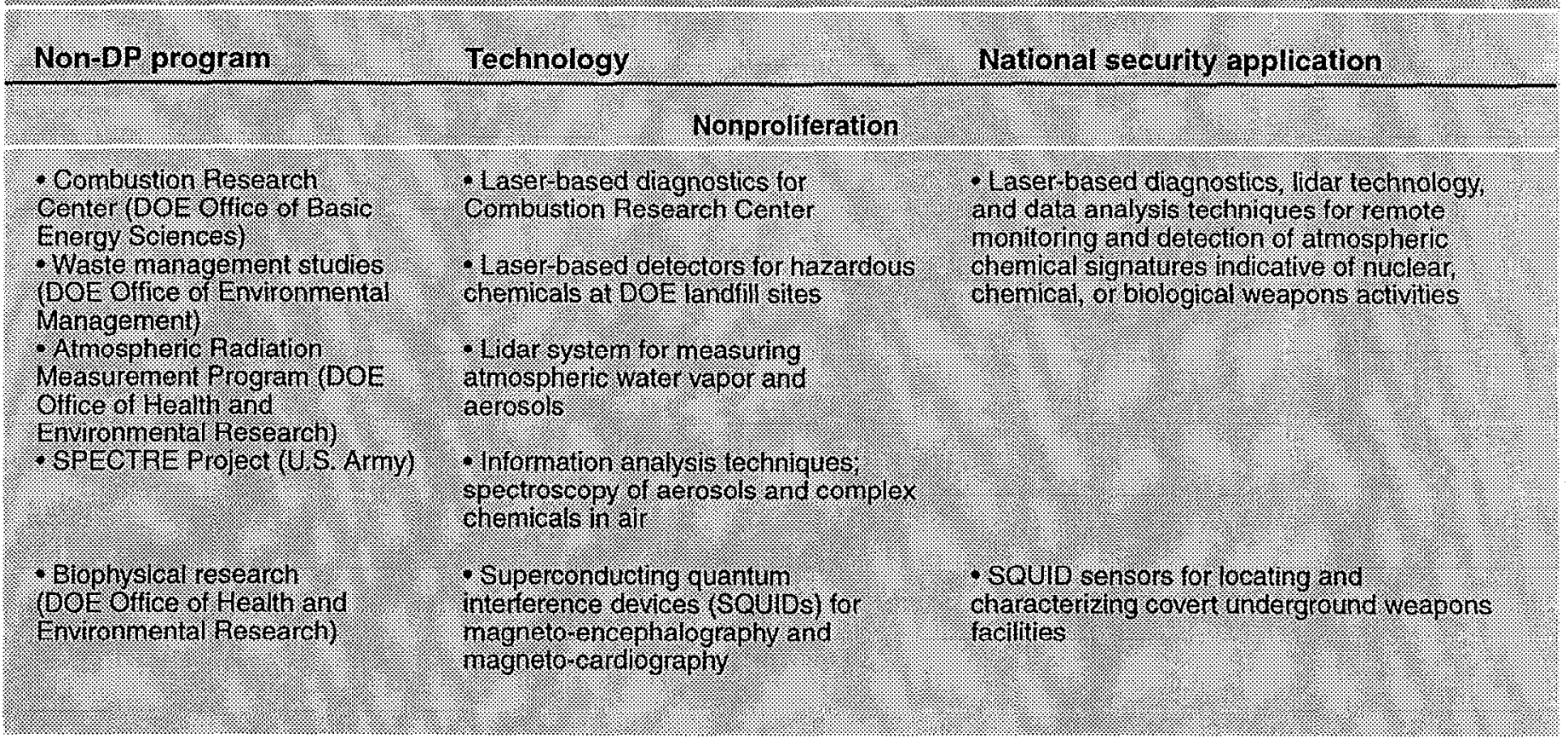

\section{Criteriag for. DP Laboratory Involvement in Other Programs}

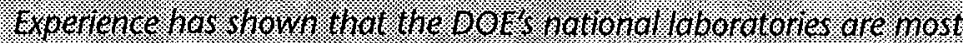
vallable when:

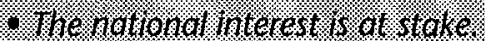

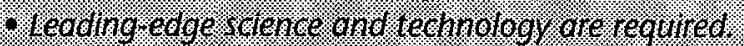

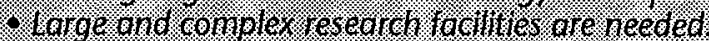

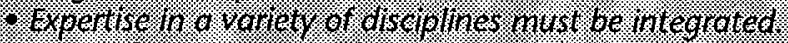

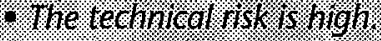

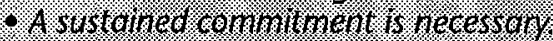

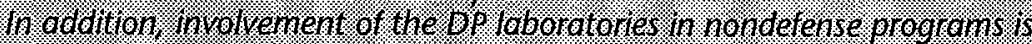

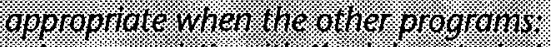

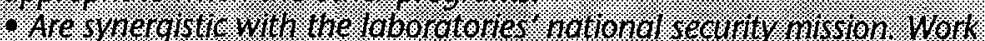

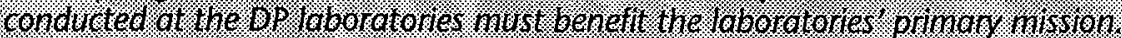

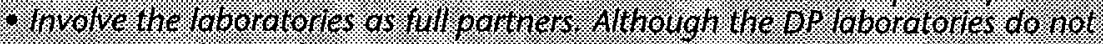

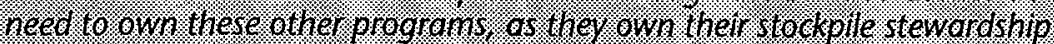

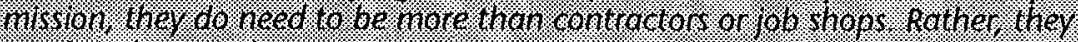

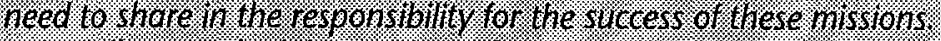

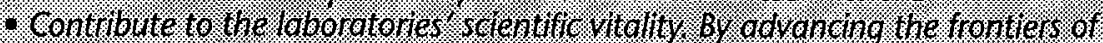

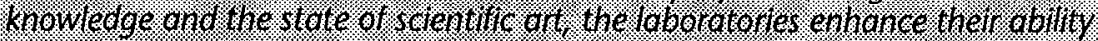

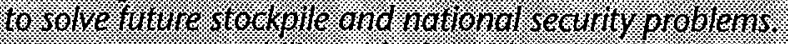

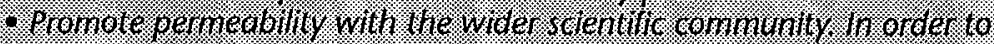

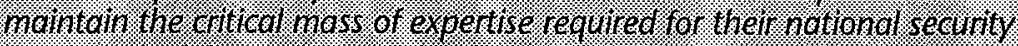

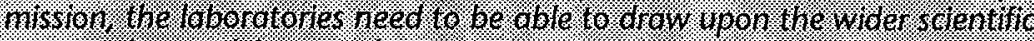

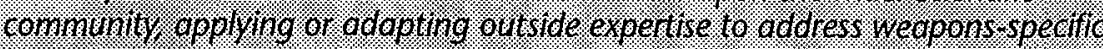
issures.

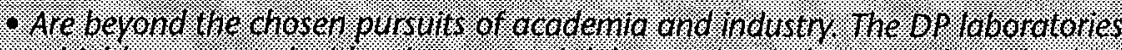

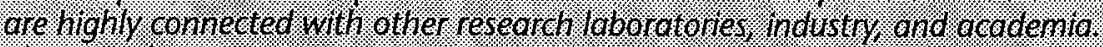

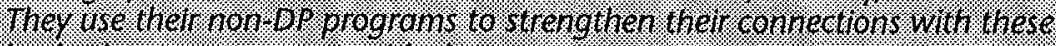

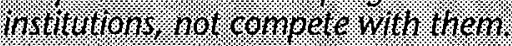

and Russia. The safe and secure disposal of this plutonium is a growing national and global security problem. The DP laboratories are working with Nevada Test Site (NTS) staff to cxamine the feasibility of disposing of excess plutonium in 4-km-dcep borcholes drilled in stable continental crust. Much of the expertise for this project comes from laboratory participation over the last decade in the Continental Scientific Drilling Project, sponsored by the DOE's Office of Basic Energy Sciences. The goal of this project was to gain an understanding of the continental crust as related to energy production, industrial minerals, and natural hazards, and the resulting experience and knowledge is proving to be directly applicable to the problem of plutonium disposal.

\section{Accelerator Production of Tritium for Stockpile Management}

An assured supply of tritium is an essential component of the 


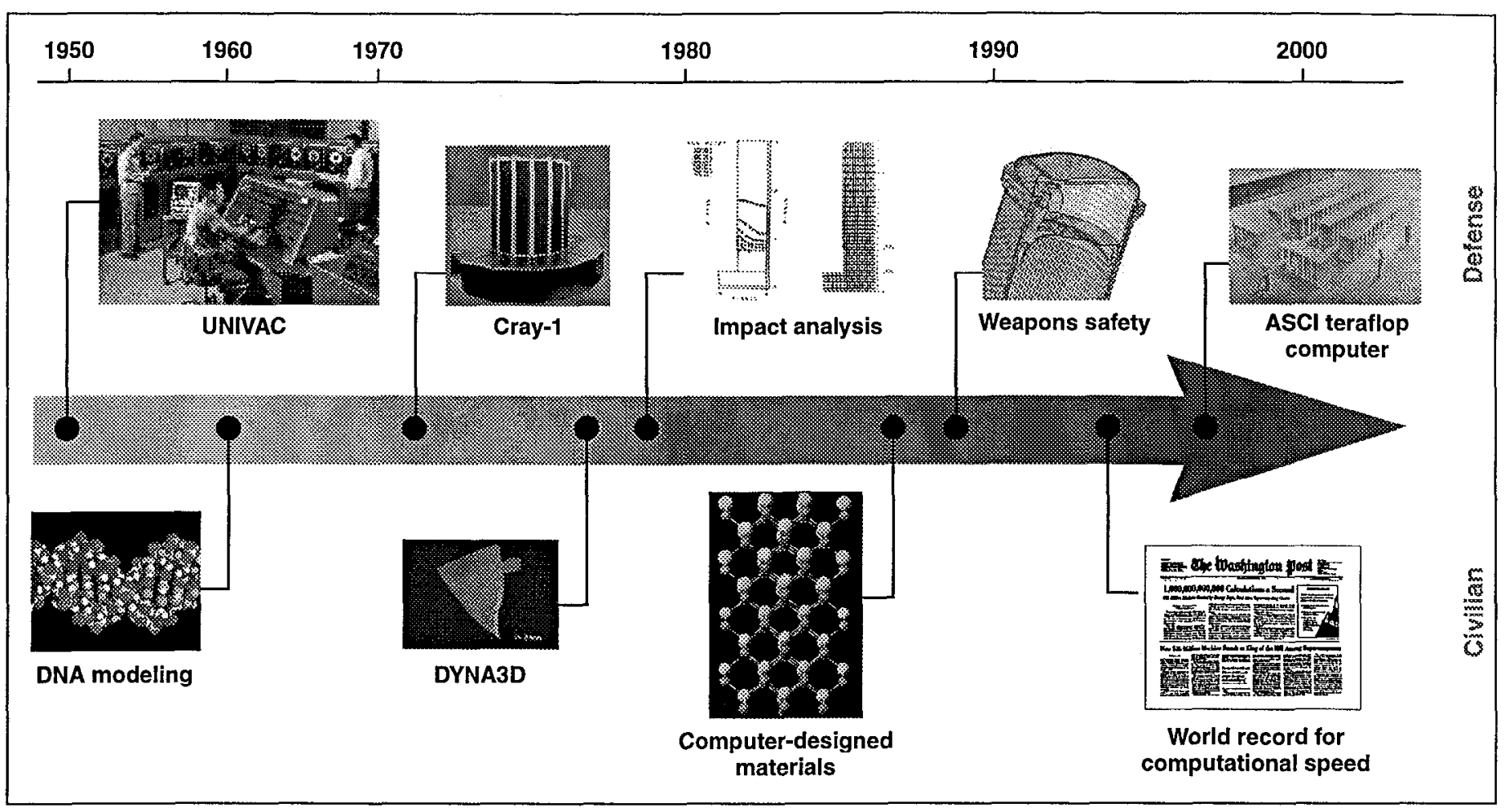

Figure 5. To meet the demands of their nuclear weapons work, the DP laboratories pioneered computing science and drove the development of supercomputers. Today, the laboratories are partnering with the U.S. computer industry in the development of the next-generation computers required to run the complex, three-dimensional numerical simulations that are required now that the U.S. has ceased nuclear testing.

Stockpile Stewardship and Management Program. Accelerator production of tritium (APT), one of two approaches being pursued by the DOE, has benefited extensively from research at the Los Alamos Neutron Science Center (LANSCE) and the Los Alamos Meson Physics Facility (LAMPF). These facilities and the research conducted there have their origins in programs supported by the DOE's Office of Energy Research.

In the 1980s, as part of the basic nuclear physics research funded by the Office of Energy Research, measurements were made at LANSCE to characterize neutron production by the bombardment of $100-$ to $800-\mathrm{MeV}$ protons on thin and thick targets made from elements ranging from beryllium to uranium. These measurements were used recently by DP researchers to develop the LAHET code system for calculating high-energy particle transport. This code is the primary design tool for the APT target.

Ongoing experiments at LANSCE are benchmarking the total neutron production in prototype APT target assemblies. Additional experiments are being conducted to optimize the tritium production efficiency of the targets. Other experiments at LANSCE are measuring radionuclide production and radiation damage in candidate materials for the APT target system. These results are being used to quantify issues related to target handling, target lifetimes, safety, and environmental impact. Continuing weapons-related work at LANSCE includes studies of material damage due to exposure to intense neutron beams, the development of advanced radiography techniques using neutron and proton beams, and tests of the effects of intense radiation on the functioning of electronic circuits.

\section{Surplus Explosives and TATB for Weapons Refurbishment}

High explosives intimately affect both the safety and performance of nuclear weapons and thus are an area of continuing concern for the DP laboratories. Stockpile life extension projects will likely require the replacement of aged explosives, the properties of which can change considerably over time. High explosives are also critical components of conventional munitions (the purview primarily of the Department of Defense). Through work with the Defense Department to develop chemical processes for disposing of surplus explosives and propellants, the DP laboratories devised a new and improved process for synthesizing TATB, the most widely 
used high explosive in modern nuclear weapons.

In years past, TATB was synthesized from 1,3,5-tricholorobenzene, which is expensive and available only from foreign suppliers (e.g., Japan, Germany, China). The laboratories' new process for synthesizing TATB uses starting materials derived from surplus Department of Defense explosives and propellants. This new process, called vicarious nucleophilic substitution (VNS), can be carried out in just two steps at ambient pressure and temperature conditions and involves no halogenated hydrocarbons. The VNS process benefits the DP laboratories' stockpile stewardship efforts in that it is less expensive, requires less energy, and uses fewer hazardous materials than the previous TATB synthesis procedure.

\section{AVLIS Technologies for Advanced Manufacturing}

Livermore's development of the atomic vapor laser isotope separation (AVLIS) process to enrich uranium fuel for civilian nuclear power reactors required the invention and productionscale demonstration of numerous technologies - copper vapor lasers, dye lasers, robotic equipment, and materials handling processes, to name a few. Several of these technologies are well suited for advanced manufacturing of weapons components.

For example, AVLIS laser technologies have been used to demonstrate the feasibility of highprecision laser cutting of weapons materials. These lasers can make very narrow, very accurate cuts, permitting precision disassembly of retired weapons and reuse of parts.
Laser-cutting technology has the potential to save a hundred million dollars over the next decade in weapons dismantlement and stockpile refurbishment efforts.

Physical-vapor-deposition processes, developed for collecting the AVLIS-separated isotope product, are being demonstrated for precision fabrication of uranium-niobium alloy parts. These parts are currently fabricated using a complex combination of forming and heattreatment operations. With the AVLIS vapor-deposition process, the uranium-niobium alloy can be deposited on a mandrel or mold, offering the possibility of single-step manufacturing for these parts.

In addition, AVLIS-developed electron-beam melting technology is being applied to recycle the uraniumniobium alloys used in weapons manufacturing. With current

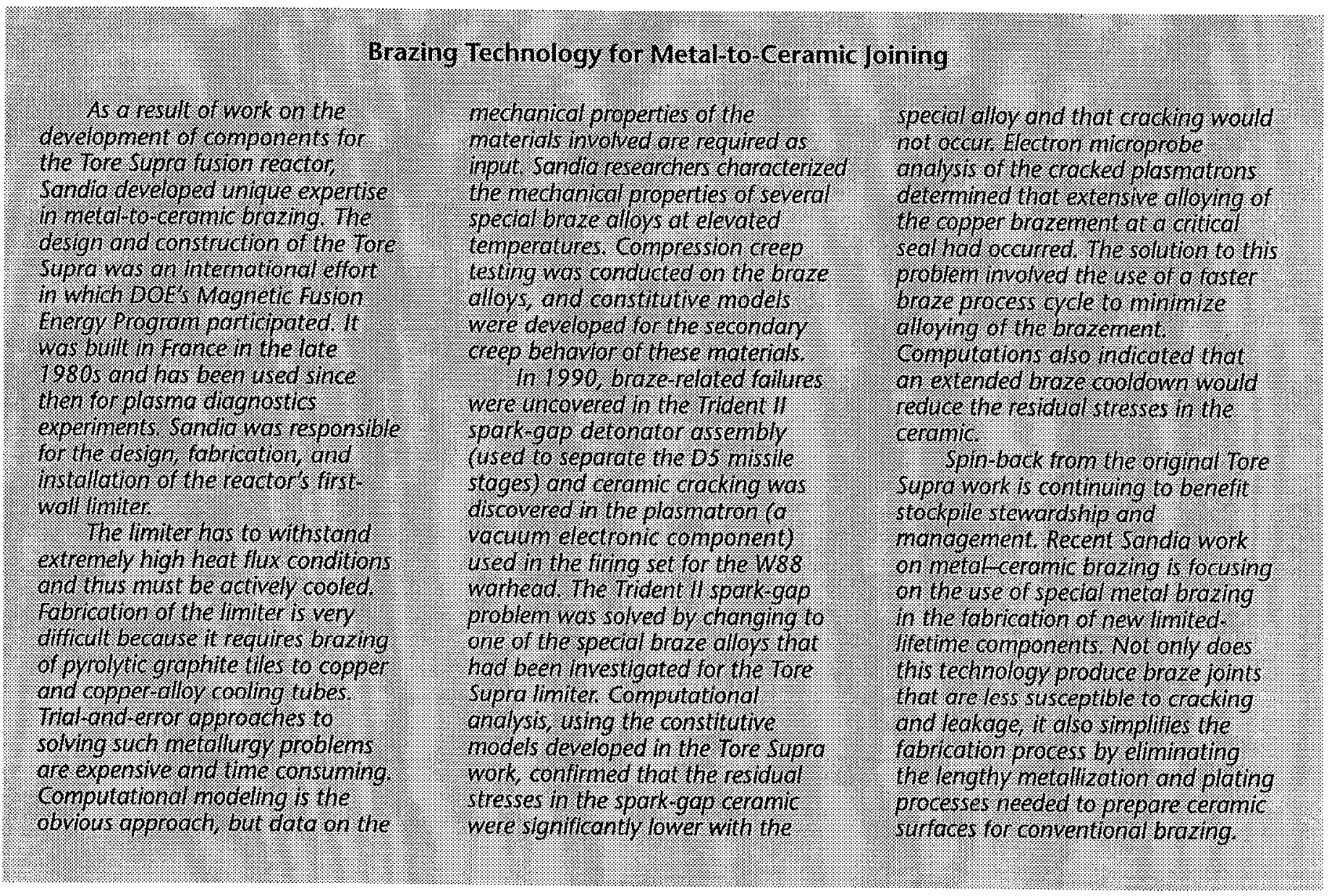


fabrication processes, less than 5\% of the alloy ends up in usable parts; the other $95 \%$ ends up as unusable scrap and waste. Electron-beam melting provides a way of recycling this scrap material, reducing the need for new alloy and decreasing the waste streams resulting from the manufacture of the uranium alloy components.

\section{Pulsed Power, Advanced Manufacturing, and Weapons Research}

Through the Repetitive HighEnergy Pulsed-Power (RHEPP) Program, funded by the Department of Defense's Strategic Defense Initiative Organization (SDIO), the DP laboratories collaborated with industry and university partncrs to develop and demonstrate the highpeak-power and high-average-power capability of magnetic switching. On the basis of these demonstrations, two high-power rapid-pulse accelerators (RHEPP I and RHEPP II) were constructed at Sandia.

The availability of these accelerators opened up many new capabilities that are directly relevant to DP missions. For instance, highpower ion beams make possible a new industrial process for surface treatment of metals, ceramics, and polymers. This process, called ionbeam surface treatment (IBEST), produces hardened, corrosion- and wear-resistant surfaces that lengthen the life and increase the reliability of various nuclear weapons components. IBEST also increases the performance of the high-power vacuum transmission lines required for pulsed-power accelerators, such as those used for $\mathrm{x}$-ray simulators and high-energy-density weapons research facilities.

In addition, using high-repetitionrate power compressors and pulsedpower systems, it is now possible to tcst accelerator componcnts much more stringently than ever before. This capability will be crucial to the development of future high-intensity test facilities for $\mathrm{x}$-ray and highenergy-density environments. For example, an advanced hydrodynamic test facility will be able to generate many frames of data at successive times, taken from multiple views, from a single hydrodynamic event, making it possible to create essentially three-dimensional movies of an implosion. The facility concept calls for the use of an accelerator to generate successive, intense bursts of $\mathrm{x}$ rays during the hydrodynamic experiment. Magnetic switching technology appears to be an excellent means of generating these multipulse $\mathrm{x}$-ray bursts.

\section{Plasma Technologies and Weapons Complex Cleanup}

Apparatus and techniques initially developed for DOE's Office of Energy Research and Office of Environmental Management are being adapted for various stockpile management applications. In particular, plasma processing technologies are being used to remove organic and nuclear materials from surfaces that are too intricate and complicated for more traditional cleaning methods. For example, initial work on plasma decontamination, funded by the Office of Environmental Management, has been extended to

\section{Erbia Coatings and Fire-Resistant Pits}

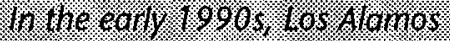

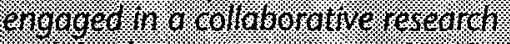

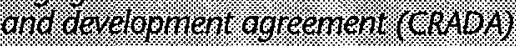

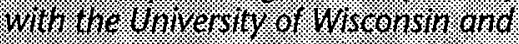

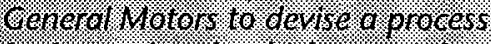

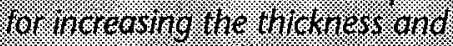
improving the adhesion of Wear resistant cortings of dionond ikes casoon on oluminuma engine pors: conventronal wisaden was that

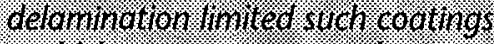

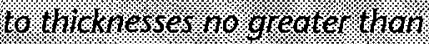

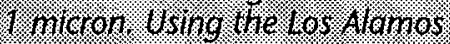

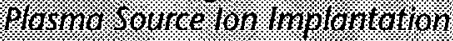

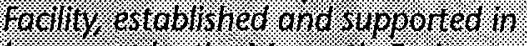

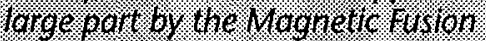
Erergy progran ond the strategic

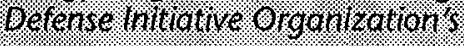

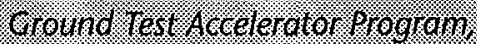

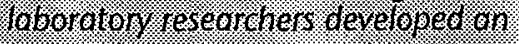
on imptantation process since

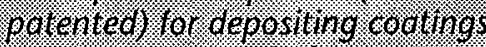
49.60 .10 mich ans thick.

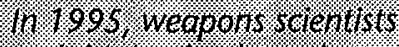

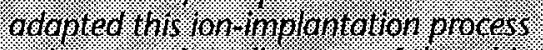

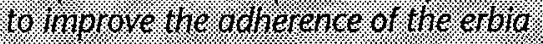

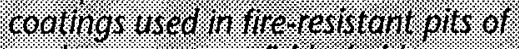

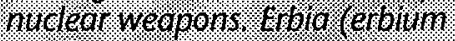

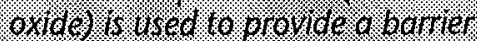

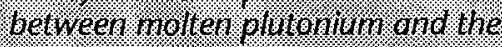

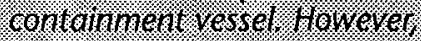

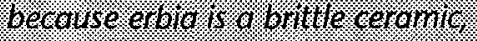
entro coatings que orone 10. delomination when subjected to thernat s ress or shod or when the

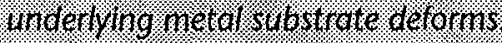

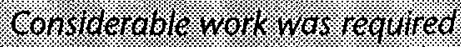

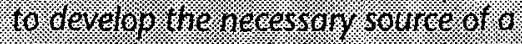
pure eronumingetal miasmogand to

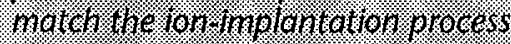
to the waracteristiss of the erbiun

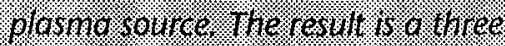

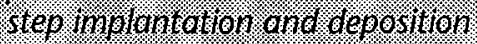

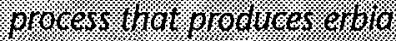
6oratings that adnere rencoroush: even When the undertymg madert substrate. is severety. detormed.

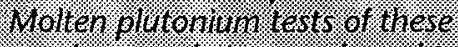

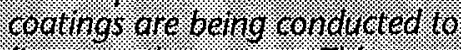

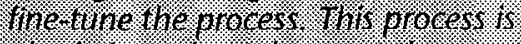

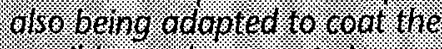

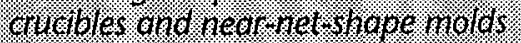

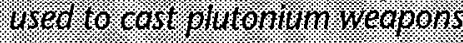
.010.0110.115. 
develop processes for cleaning organics from the interior surfaces of 6-foot-long gloveboxes. This process is also being adapted to the removal of depleted uranium from blast shields used for hydrodynamics tests. In addition, a plasma physics research facility at Los Alamos, originally developed under the auspices of the Office of Energy Research, is being used for large-scale reactive ion etching to remove organics and actinides from contaminated apparatus and devices. Also, through various collaborative activities with industry, the DP laboratories are "importing" best commercial practices in plasma cleaning and etching from the microelectronics industry.

\section{Materials Science Studies and Stockpile Aging}

Atom-level materials science studies, funded in large part by DOE's Office of Basic Energy Sciences, are benefiting the materials aging research required for enhanced stockpile surveillance. For example, the interfacial force microscope makes it possible to examine interfaces of adhesively bonded materials at the level of individual atoms. The imaging technique was first explored using Laboratory Directed Research and Development funds; it then became the focus of a Basic Energy Sciences program to study fundamental aspects of interfacial adhesion. This new microscopy technique is now providing a molecular basis for modeling and predicting the performance of adhesive joints in weapon components.

Important contributors to agingrelated concerns in stockpile weapons are the changes in chemistry, phase constituency, and adhesion of interfaces that occur over time. Virtually all weapon components contain critical interfaces between dissimilar materials-films deposited on ceramic substrates, encapsulated components, adhesively bonded and laminated components, etc. Aging of these materials frequently results in the segregation of impurities into precipitates that, in turn, introduce microscopic flaws and cause a loss of adhesion. Flaws and stresses can

\section{The National Energy. Research Supercomputing Center}

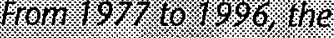
Nationd Eherov Resear ch

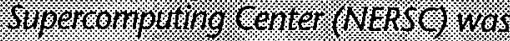
sited or and oberateo by Livemore

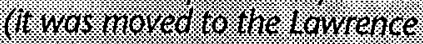

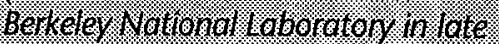

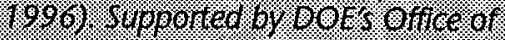

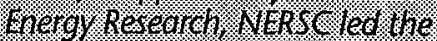
develupment of high end

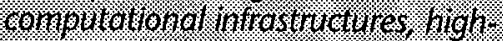
speed networks, ond advonated

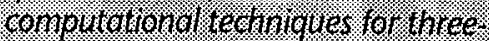

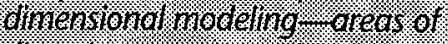
ditreat importance to ve the

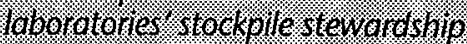
chorge.

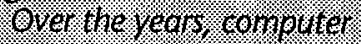

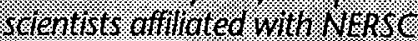

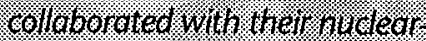
nearoons orogron golleagues in the development of cempunational

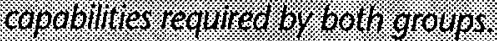
for example the vational Storage

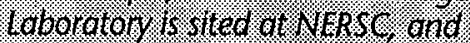

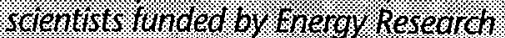
Worked logenther with IOP researohers to develop the Gigh o oertornthe storage ofstem. Wis colloboration s

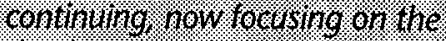
development of a high pertomance storoge system tor porallet

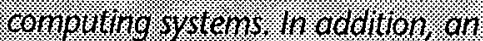

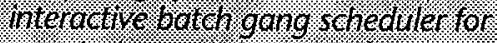

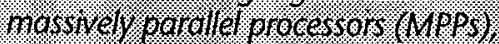
developed by WLRYC ntovides enormags Hexibimu in the rse ond?

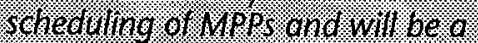
ker. cantitivutor to the noreases in

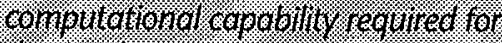

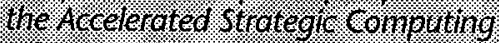

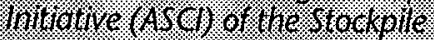
Gevordship ond whongenent Program.

VLRSOL olso housses the Energ:

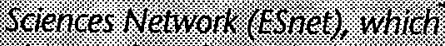

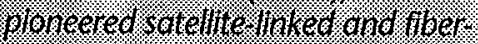

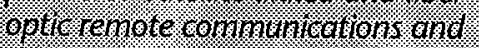

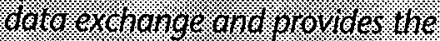

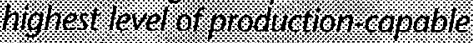
networting in the hotion. 1 be: capabilities or the ES net and the

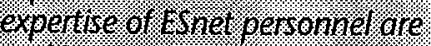
waktho essentivil contubutions to

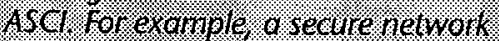

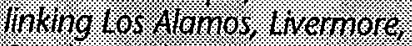

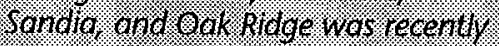
approved for t ransmisston or classified Gate ond witt soon be extended to: the weopons. production plants.

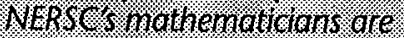
Wordorenowned tor ther adaphie mesh retinem nent techigures. and the Do toboratores nivlear Weapons progrom Whs benefited form their ad vanced computational tools. lor exangete. porralle! radiation alffustion sonvers. based

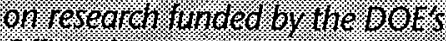

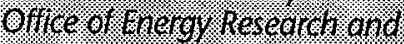
conousted dit NeBsC, are betho

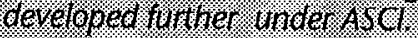

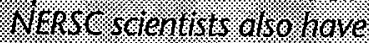

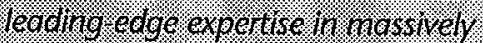

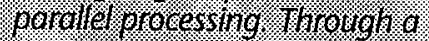

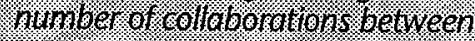

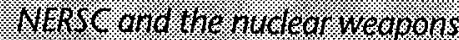

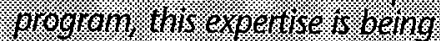

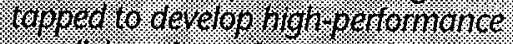
ograllel vet sions of a withe of: Weapons nodelify acodes.

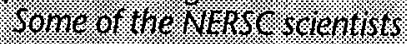
hove romed vivernores classified.

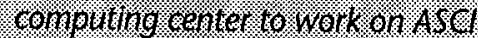
ind other derense-riblad projects

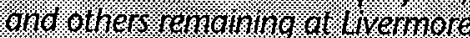

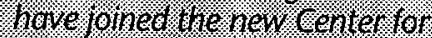
Applied Sichentific ormputing.

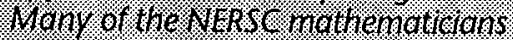
have noved fo whence Berketey armo meir collaboration. with

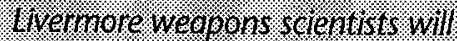
Gombinue under contrad. 


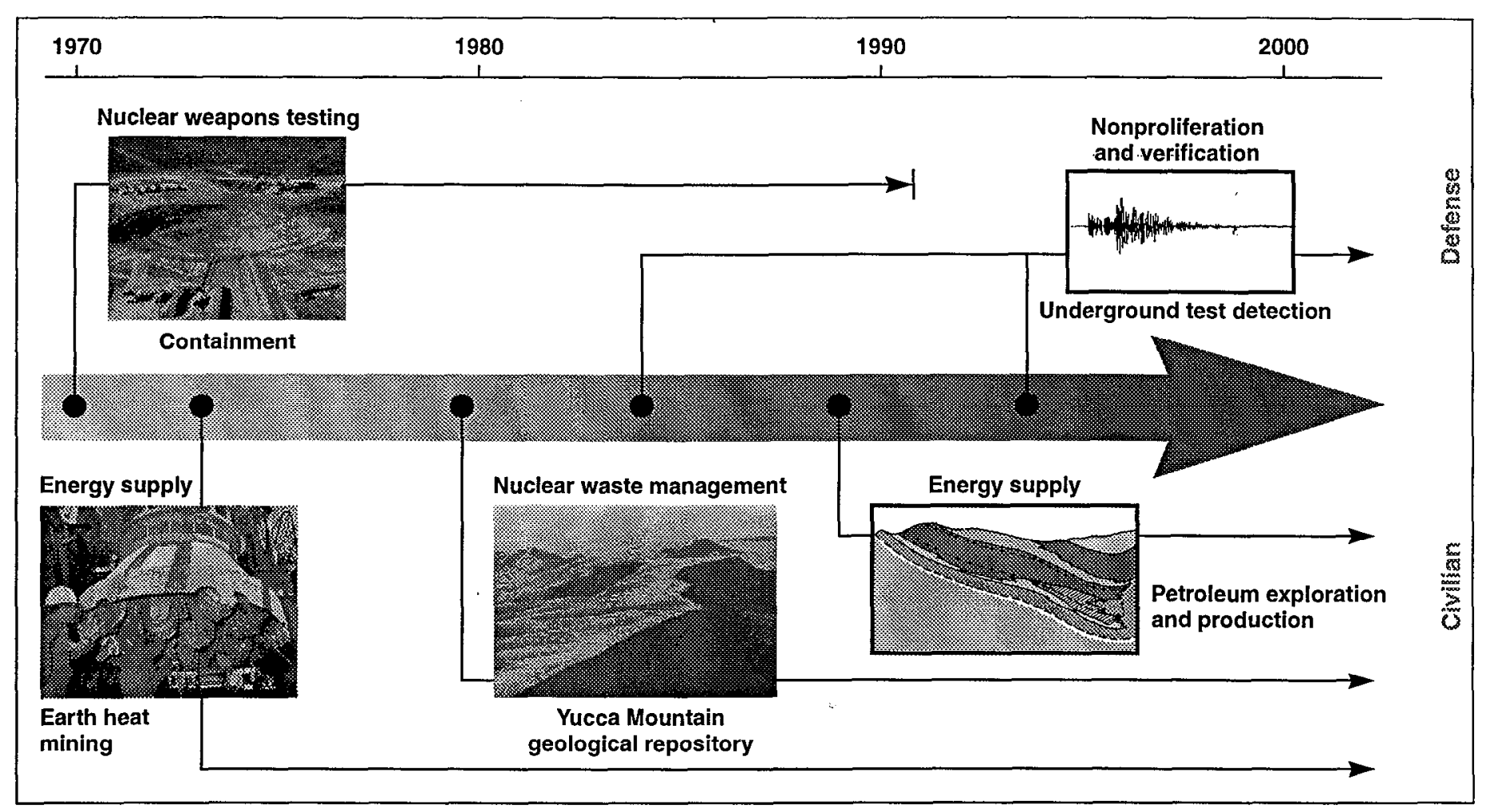

Figure 6. DP laboratory expertise in geology, geochemistry, hydrology, seismology, deep drilling, and other aspects required for underground nuclear testing has spun out to benefit the oil and gas industry, has been integral to the continuing effort to design underground nuclear waste repositories and is now central to monitoring and verification of the Comprehensive Test Ban Treaty.

accumulate and cause the adhesive bond to rupture and the component to fail. Interfacial force microscopy is providing essential fundamental information for the development of accurate models of the effects of aging on adhesive interfaces. Once the models are validated with experimental data, they will be used to assess structural integrity and predict failure of these bonds.

\section{SQUIDs, Brain Imaging, Nonproliferation, and Stockpile Surveillance}

Superconducting quantum interference devices (SQUIDs) are presently the most sensitive magnetic sensors known, able to measure magnetic fields as small as a few femtotesla $\left(10^{-15} \mathrm{~T}\right.$, less than a billionth of the Earth's magnetic field). The ultrasensitivity of these sensors is opening new areas of research and new applications for electromagnetic sensing and detection methods. Indeed, the measurement of magnetic fields from living organisms, or biomagnetism, is a rapidly growing field that owes its existence almost exclusively to the extraordinary sensitivity of SQUIDs.

DOE's Office of Health and Environmental Research recently funded one of the DP laboratories to develop techniques for using SQUID sensors in biomagnetic applications in magneto-encephalography (MEG) and magneto-cardiography (MCG). Through a CRADA with a California company, this technology has been developed into a large MEG sensor system that will cost one-quarter that of previously available commercial systems.
SQUID technology from these biomagnetism studies is being applied to such defense and nonproliferation problems as locating and characterizing covert underground weapons facilities, locating land mines and unexploded ordnance, nondestructive evaluation of defects in stockpile weapons, and discrimination of the contents of storage drums for verification of international arms control, dismantlement, and nonproliferation agreements. For example, recent experiments have demonstrated the feasibility of using SQUID technology to detect underground structures and hidden weapon pits. Advanced stockpile surveillance technologies using SQUID sensors are also being developed to nondestructively evaluate material defects and corrosion in weapons components. 


\section{Advanced Photonics and Nuclear Test Readiness}

Photonics is an essential nuclear weapons technology, both for weapons components and for underground nuclear testing. The DP laboratories are maintaining their cutting-edge expertise through weapons-related activities and through non-DP projects. Photonics technology is being incorporated into stockpile nuclear weapons to increase safety and reliability. One example is the all-optical fireset, in which optical fibers replace the electrically conducting cables currently used.

With the cessation of nuclear testing, the DP laboratorics have found other ways to maintain expertisc in test-related photonics. (Fiber optics are used to rapidly transmit large quantities of data from the buried nuclear test device to the recording instruments at the surface.) The laboratories are involved in a number of non-DP projects that are extremely challenging and require cutting-edge information technology. For example, photonics are integral to the optical interconnects intended for massively parallel computing systems and to the high-speed optical networks required for highperformance telecommunications. The Defense Advanced Research Projects Agency (DARPA) is taking advantage of the DP laboratories' expertise in photonics, funding $R \& D$ in optical interconnects and advanced optical networks to meet the Defense Department's need for improved battlefield communications and information transmission (e.g., threedimensional terrain visualizations derived from satellite data).

The R\&D on optical interconnects and optical networks conducted for DARPA is being directly applied to the Accelerated Strategic Computing Initiative (ASCI). The computing performance (a ten-thousandfold improvement over current capabilities) and the connectivity of remote sites required for the Stockpile Stewardship and Management Program cannot be accomplished without advanced photonics technologies like optical interconnects. DARPA-sponsored R\&D on automated packaging of the optical interconnects will greatly reduce the cost of this essential technology. Thus, by advancing the photonics technology for telecommunications and highperformance computing, the DP laboratories are maintaining essential nuclear-testing capabilities.

\section{Geoscience, Energy Resources, and Treaty Verification}

The DP laboratories are involved in several partncrships with individual oil and gas companies and with industry-wide consortia to build on the laboratories' specialized abilities in seismology, flow and transport simulations, and related areas of geoscience. During the energy crisis of the 1970s, this expertise was applied to develop the hot-dry-rock alternative energy technology (sponsored by DOE's Office of Basic Energy Sciences). The concept involved the engineering of an underground heat exchanger to extract the Earth's natural heat and convert it to a usable energy source. In the late 1970s, knowledge gained from the hot-dry-rock project was applied in the development of a geologic repository for spent fuel from civilian power reactors. In the 1980s and 1990s, DP laboratory expertise in geoscience and seismology was further extended to develop seismic techniques for detecting underground nuclear tests in distant regions, a continuing national security need for monitoring the recently signed Comprehensive Test Ban Treaty (Figure 6).

\section{Laser Diagnostics, Remote Sensing, and Nonproliferation}

\section{Shortly after the laser was invented in the 1960s, the DP} laboratories began developing laserbased diagnostic instruments, first for weapons experiments (e.g., to better understand gas flows in gastransfer systems) and later for experiments in fusion research, high-pressure physics, and combustion science. Indeed, laserbased diagnostics are integral to the unique experimental capabilities of the Combustion Research Facility, established by the DOE's Office of Basic Energy Sciences at Sandia. Much DP laboratory expertise in laser diagnostics is a direct result of work at this facility.

Laser diagnostics have found increasing use in a wide variety of programs requiring remote sensing and monitoring. For example, the DOE's Office of Environmental Management funded the development of laser-based instrumentation to detect and monitor hazardous chemicals (e.g., volatile organic compounds) at laboratory landfill sites. In the early 1990s, a lidar system (the laser analog of radar) was developed by the DP laboratories to measure atmospheric water vapor and aerosols for the Atmospheric Radiation Measurement Program, sponsored by the DOE's Office of Health and Environmental Research.

Lidar and other laser-based remote-sensing technologies developed through such non-DP projects are finding extensive use in nonproliferation programs. For example, the CALIOPE (Chemical Analysis by Laser Interrogation of Proliferation Effluents) Program is developing laser-based remote-sensing technologies for detecting the chemical signatures of nuclear proliferation activities. These remote-sensing programs require innovative work in 
other areas, such as determining the wavelengths of laser light to stimulate fluorescence from the chemicals being monitored and computer algorithms for unfolding the spectral signatures of the targeted chemicals.

Other national security programs are building off the CALIOPE Program. For example, the Army's SPECTRE Project for detecting biological warfare agents is pushing the limits of the information-analysis techniques developed by the DP laboratorics for CALIOPE. SPECTRE is also stimulating advances in the spectroscopy of aerosols and complex chemicals to broaden U.S. capabilities for detecting signatures of weapons proliferation activities. Advances made through SPECTRE are spinning back not only to CALIOPE but to many elements of national security and nuclear weapons work at the DP laboratories.

\section{Multiprogram Synergy in the Future}

The benefits of the DP laboratories' multiple programs will continue in the future. For example, advances in supercomputing, developed through the ASCI project, will spill over into the wider scientific and civilian sectors. Completely new computing capabilities will arise from the ten-thousandfold increases in computing power, data storage, and network speed and from the simulation and modeling advances that are the goals of ASCI. Since much of the ASCI work is being done in collaboration with industry, ASCI spin-outs will be readily transferred to the private sector.

Advanced materials, processes, and manufacturing technologics developed for stockpile refurbishment will have similarly broad-rcaching spin-outs. Miniaturized electronics, sensors, and other devices developed for enhanced stockpile surveillance will give rise to a host of micromachines and imaging technologies for industrial, medical, environmental, nonproliferation, and consumer applications. New materials will lead to new consumer products. Improved manufacturing processes will benefit industry (and the public) through increased productivity, reduced environmental impact, and decreased costs.

Fundamental scientific researchwhether conducted for programs in climate change, advanced energy technologies, or environmental remediation or for collaborations with academia and industry - will contribute to the knowledge and skill bases required for stockpile stewardship and management. Advances in three-dimensional simulation, being developed through climate modeling work, will be directly applicable to the modeling needs of stockpile stewardship. Improved understanding of materials behavior under extreme conditions, gathered through fusion energy research, will benefit studies of materials interactions and aging in stockpile weapons. Remote-sensing technologies, developed for environmental monitoring and remediation, will find application in the DP laboratorics' stockpile surveillance and nonproliferation programs.

Synergism among the DP laboratories' multiple programs and between the laboratories and the wider scientific community greatly accelerates the pace of technical innovation and scientific problem solving. Indeed, much of the power of science comes from open communication and critique across disciplines and programs. Significant and often unexpected discoveries emerge from the productive friction that occurs when different perspectives rub against each other and spark new insights. With federal funding for scientific R\&D tightly constrained, this productive friction is essential. 


\section{Conclusion: Multiple Programs Enhance the DP Laboratories' National Security Mission}

SINCE the inception of the DP laboratories, the challenge and importance of their national security mission has required and attracted some of the most talented and skilled scientists and engincers in the nation. The laboratories' history of scientific and technical achievement attests to the outstanding creativity of these individuals. The dual charges of science-based stockpile stewardship and nuclear readiness present challenges of the magnitude and importance that will continue to require and attract top-caliber scientists and engineers to the DP laboratories.

In addition, an increasing number of nationally important issues involve science and technology - preserving the environment, developing new sources of energy, inventing nonpolluting manufacturing processes, improving health care, enhancing economic prosperity, as well as ensuring national security. The three DP laboratories can make unique and valuable contributions in all of thesc arcas.

By working on multiple programs, including those not directly related to stockpile stewardship and management, the laboratories' scientists and engineers are able to take different approaches to technical issues, view problems from new perspectives, and apply their skills and knowledge in different ways. These other programs also bring the laboratories' scientists and engineers into contact with the wider scientific and technical community, creating an environment of collaboration and synergy.

By engaging in appropriate nondefense programs in addition to thcir nuclcar weapons work, the Los Alamos, Livermore, and Sandia laboratories sustain their cuttingedge expertise in a broad range of science and technology and thereby maintain the institutional vitality required for their national security mission. In so doing, they ensure their ability to make science-based certifications of the safety and reliability of the enduring U.S. nuclear stockpile and to meet their nuclear readiness mandate. They also make unique contributions to other programs that are critical to the nation's security and well-being. 


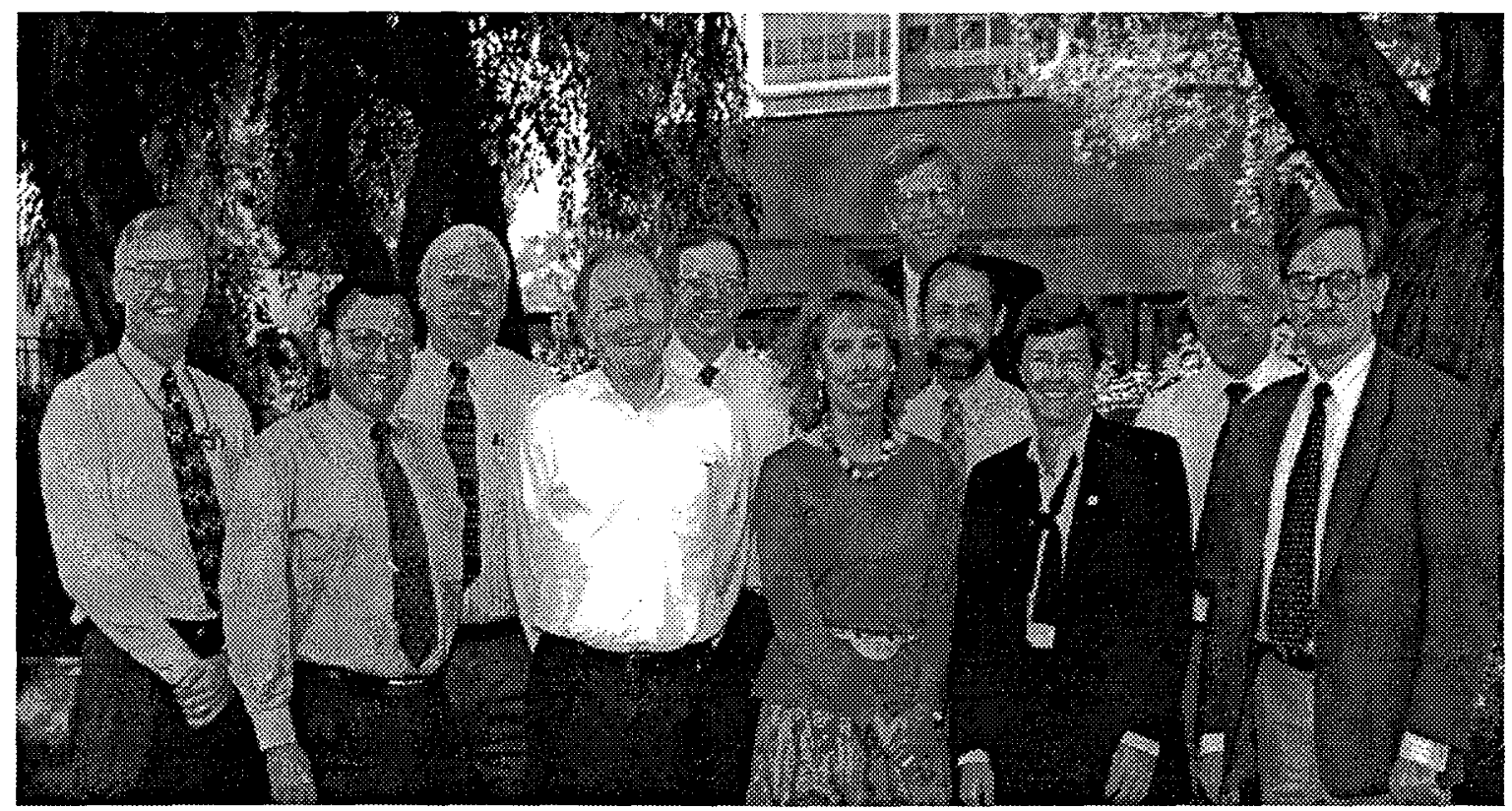

\section{DOE and Laboratory contacts: Left to right)}

John Cummings (Sandia)

Maurice Katz (DOE/DP)

Robert Eagan (Sandia)

Richard Fortner (Livermore)

Jay Edgeworth (DOE/DP)

Lauren de Vore (Livermore, writer/editor)

Carl Poppe (UC)

Paul Shoemaker (Sandia, facilitator)

Kim Thomas (Los Alamos)

Andrew Hazi (Livermore)

Peter Barnes (Los Alamos)

\section{DISCLAIMER}

This product was prepared as an account of work sponsored by an agency of the United States Government. Neither the United States Government nor any agency thereof, nor any of their employees, makes any warranty, express or implied, or assumes any legal liability or responsibility for the accuracy, completeness, or usefulness of any information, apparatus, product, or process disclosed, or represents that its use would not infringe privately owned rights. Reference herein to any specific commercial product, process, or service by trade name, trademark, manufacturer, or otherwise does not necessarily constitute or imply its endorsement, recommendation, or favoring by the United States Government or any agency thereof. The views and opinions of authors expressed herein do not necessarily state or reflect those of the United States Government or any agency thereof. 